$$
\begin{aligned}
& \text { أثر رأس المــال الفكــى }
\end{aligned}
$$

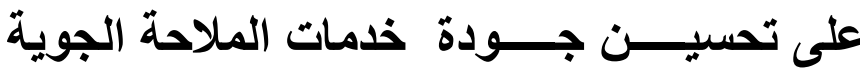

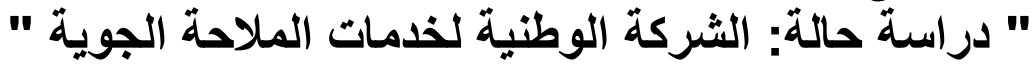

The Impact of the Intellectual Capital's

On Improving the Quality of Air Navigation Services

" A Case Study on: National Air Navigation Services Company"

$$
\text { إعداد الباحث }
$$

حسام أحمد على أحمد حماده 


\section{مستخلص الدراسة}

استهدفت الاراسة توضيح دور رأس المـال الفكرى فى تحسين جودة الخدمة الملاحية المقدمة للعملاء من خلال اختبار مدى وجود علاقة بين المكونـات الرئيسية لرأس المسال الفكرى وجودة

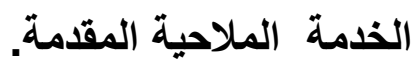

وتوصلت الدراسة إلى وجود علاقة ارتباط معنوية ذات دلالة إحصائية بين مكونـات رأس المسال

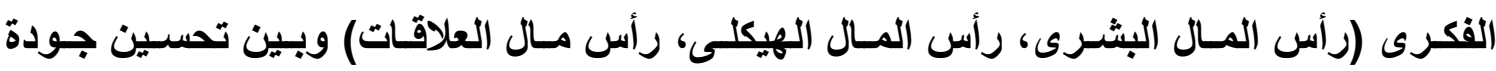

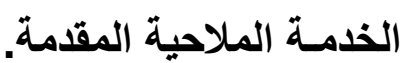

كما توصلت الدراسة إلى وجود تأثير معنوية ذات دلالة إحصائية بين مكونات رأس المسال الفكرى

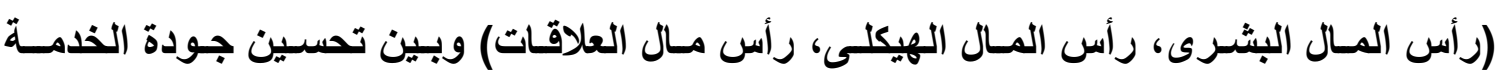

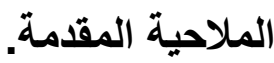

مما يدعم التوصية بضرورة العناية والاهتمام بمكونات رأس المسال الفكرى (رأس المال البشرى،

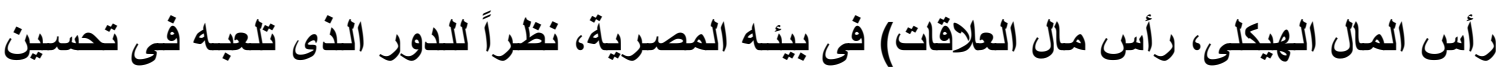
جودة الخدمة الملاحية المقدمة للعملاء وتحقيق الأهداف المخططة. 
- 148 - 


\section{ABSTRACT:}

The study aimed at clarifying the role of intellectual capital in improving the quality of navigational service provided to customers by examining the relationship between the main components of intellectual capital and the quality of the navigational service provided.

The study found a significant correlation between the components of intellectual capital (human capital, structural capital, capital of relations) and improvement in the quality of the navigational service provided.

The study also found a significant statistical significance between the components of intellectual capital (human capital, structural capital, capital of relations) and improving the quality of the navigational service provided.

This supports the recommendation that attention should be paid to the components of intellectual capital (human capital, structural capital, capital of relations) in the Egyptian environment due to the role it plays in improving the quality of the navigational service provided to customers and achieving the planned objectives. 
لقد تزايد الاهتمـام والوعي في الآونـة الأخيرة للدى جميع المنظمسات على مختلف مستوياتها،

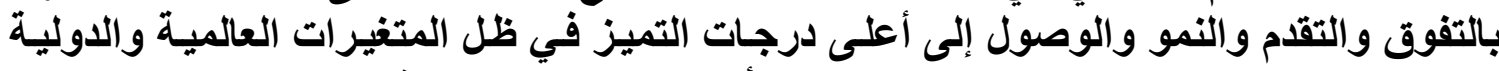

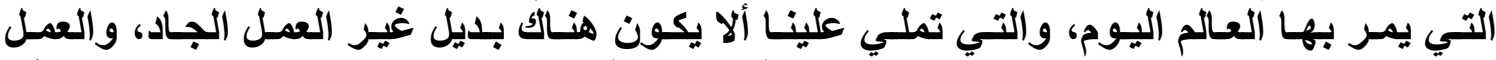

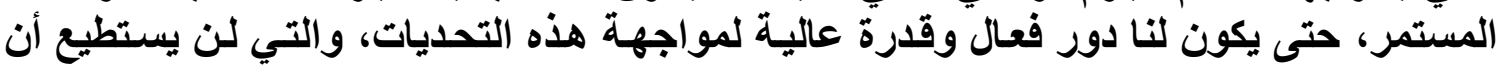
يواجهها إلا من يؤمن بأن الجودة في الأداء هي السبيل إلى الاستمرار والتهول التطور.

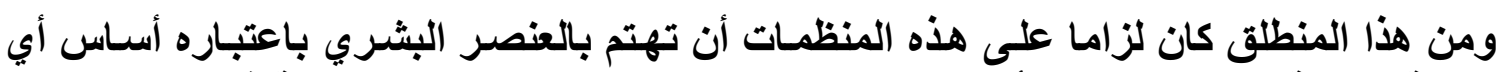

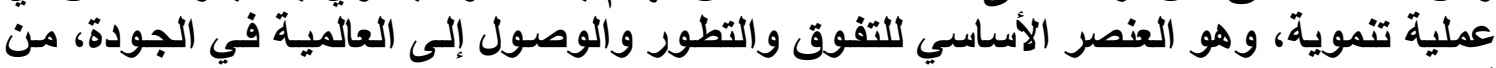

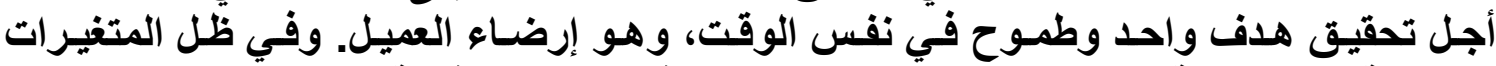

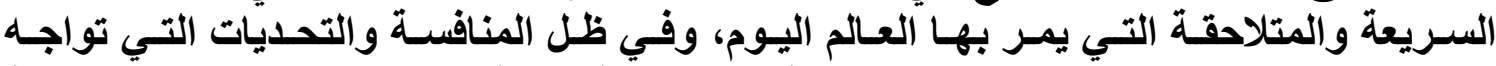

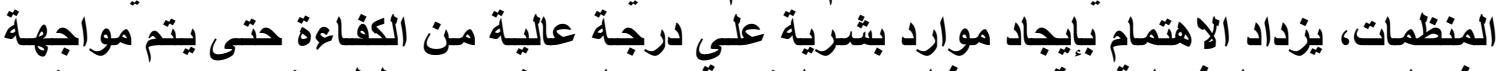

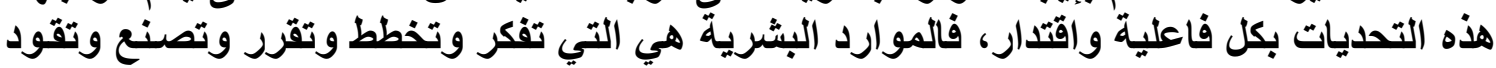

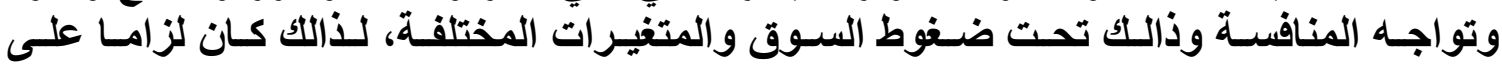

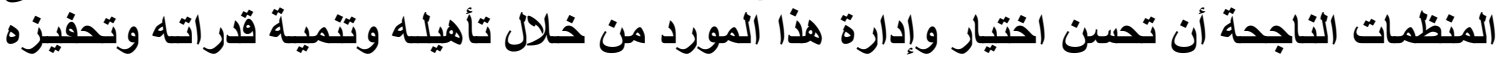

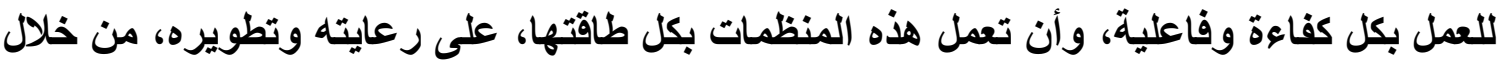

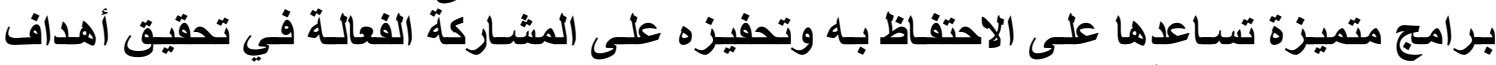
واستراتيجيات المنظمة ورؤيتها.

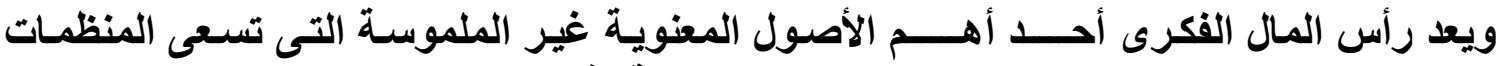

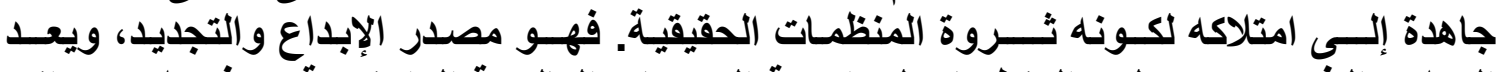

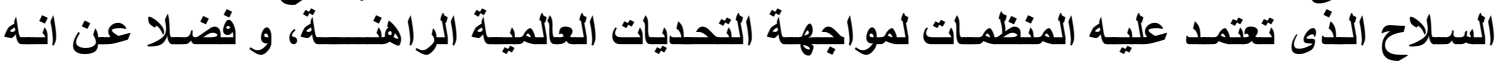

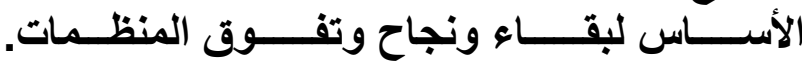




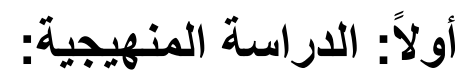
1/1 - 1 أهمية البحث:

أ.يساهم البحث فى تأصيل مفهوم رأس المال الفكرى وتحديد مكوناته الأساسية وأفضل الأساليب

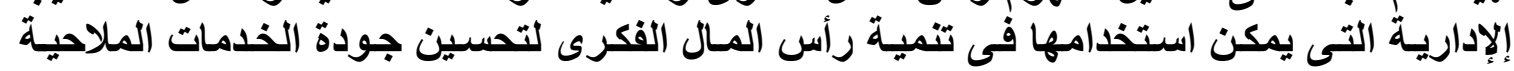

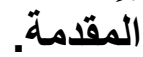

ب. يساعد هذا البحث فى تحديد أوجه القصور في إداره رأس المـال الفكرى في المنظمة محل

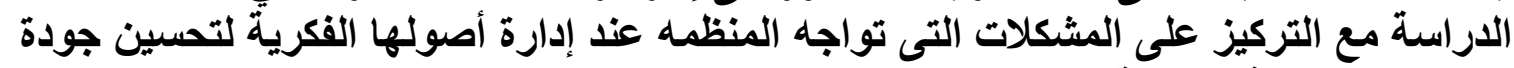
الخمات الملاحية المقدمة.

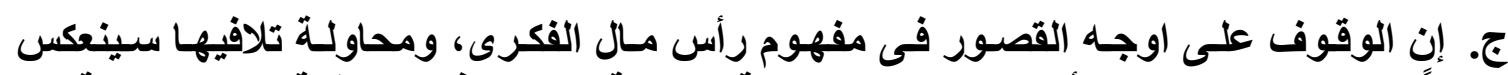
ايجاباً على تحسين مستوى أداء الخدمات الملاحية المقدمة للعملاء فى المنظمة محل الاراسة.

2/1 - 2/1 الاراسة الاستطلاعية:

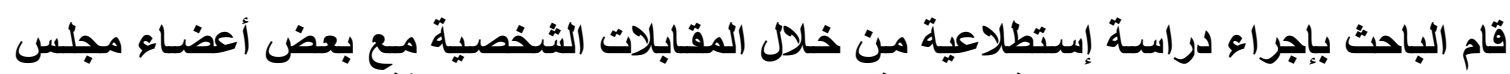

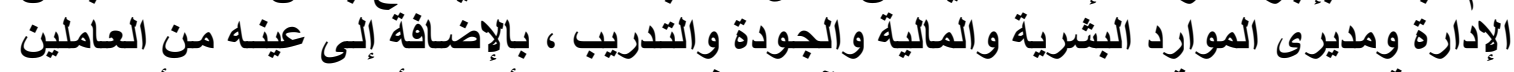

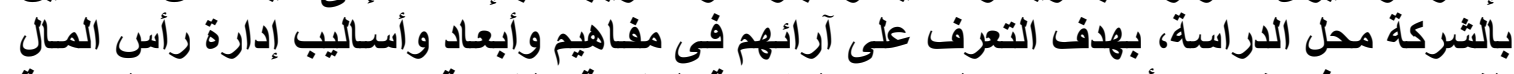

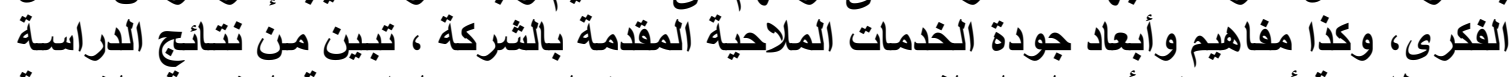

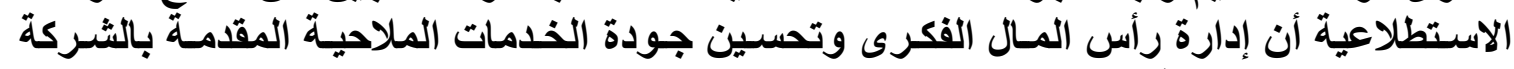

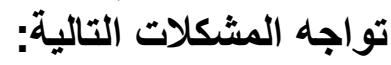
أ.انخفاض الجهود التى تبذلها إدارة الثركة لاستقطاب العاملين ذوى القبرات الإبداعية.

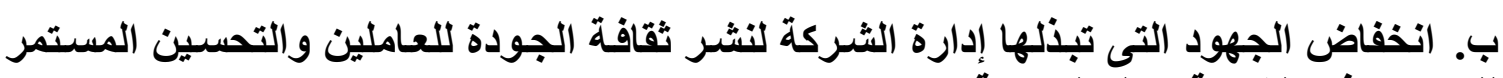
ل ل لخدمات فى الثركة محل الاراسة. ج. وجود قصور من جاتب إدارة الثركة في تعريف العاملينة القائمين بتقديم الخدمات بالثركة محل الدراسة، بمفاهيم وأبعاد ومقاييس جودة الخدمة المقدمة للعملاء.

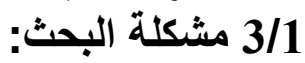

علي الرغم من قيام الثركة باتباع الأسباليب الإدارية الديثة، إلا أن هناك العديد من المشكلات

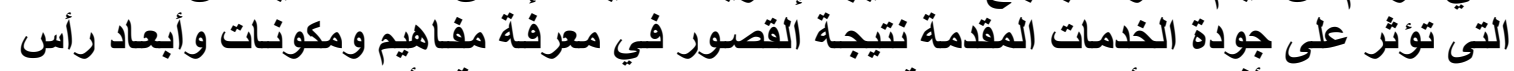

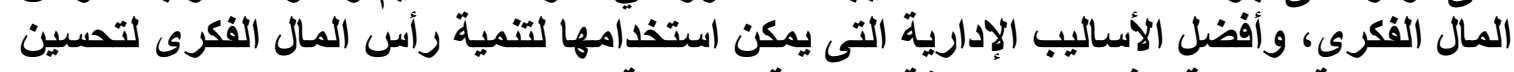

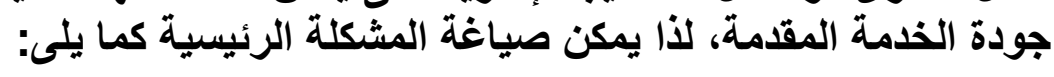

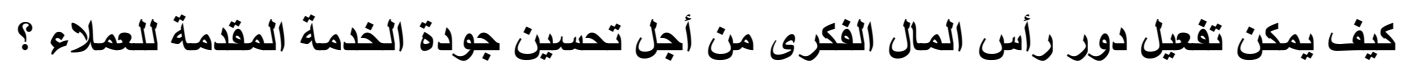




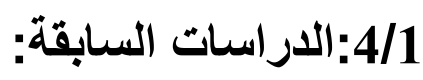
1/4/1 دراسة (Sharabati,2008) والمقدمة بعنوان:-

The Effect of Intellectual Capital on the Performance of Pharmaceutical Manufacturing Organization in Jordan.

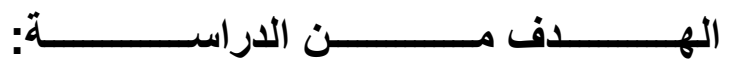

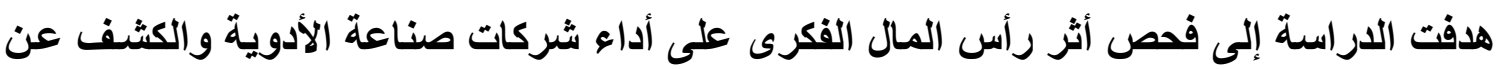

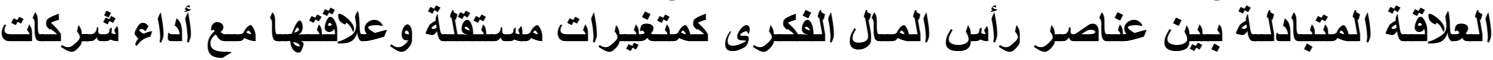

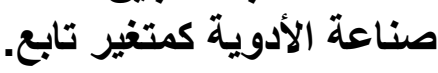

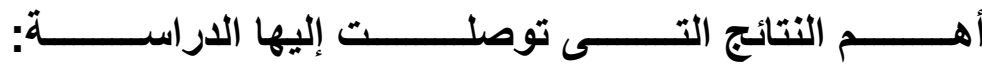
1- كثفت الدراسـة إلى وجود علاقة مباثرة وإيجابية بين رأس المسال الفكرى وأداء شركات صناعة الأدوية الأردنية. 2- إن شركات صناعة الأدوية تركز على رأس المسال البشرى ورأس المسال العلاقاتى أكثر من

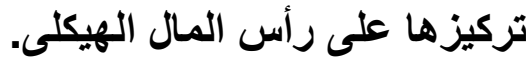
2/4/1 دراسة (Hormiga, et Al., 2010) والمقدمة بعنوان:-

The Role of Intellectual Capital in the Success of New Ventures.

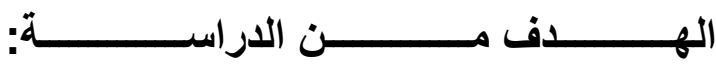

هدفت الدراسة إلى كثف تأثير رأس المال الفكرى بأبعاده فى نجاح المشاريع الجديدة، كما سعت الاراسة إلى تحليل رأس المال الفكرى ضمن مشاريع الأعمال.

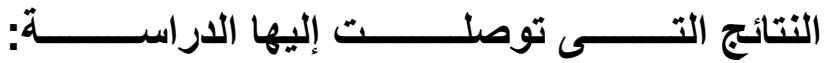
أهـ

وجود علاقة بين الموجودات غير الملموسة ونتائج الثركات الجديدة، كما أثشارات إلى أهمية

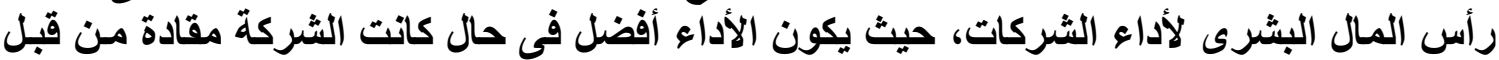
فريق يسوده روح الرضا والتعاون والتواصل، كما أفادت الدراسة أهمية تعميق أبعاد رأس المال

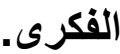




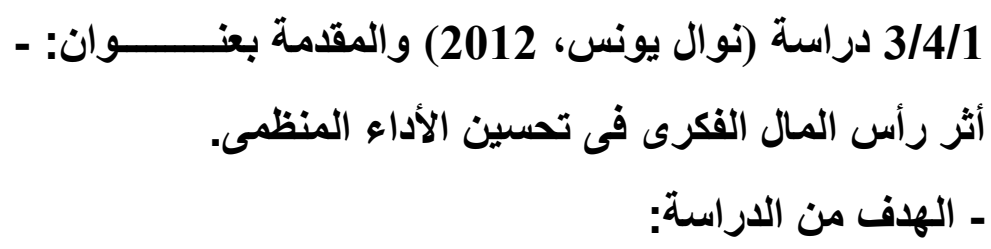

يسعى البحث إلى تحديد وتثخيص العلاقة التأثيرية بين متفيرات رأس المـال الفكرى فى تحسين

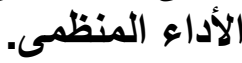
ـ أهم النتائج التي توصلت إليها الدراسة:

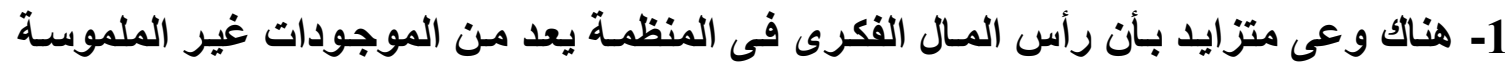
والمهمة وأن تفعيل هذا المورد من خلال استثماره يوفر قدرة كبيرة للفئل للمنظمة لتحسين الأداء.

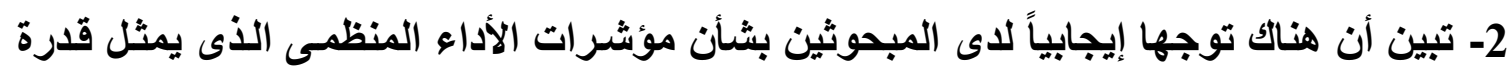

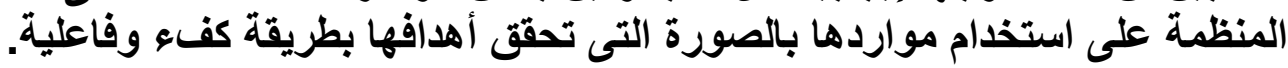

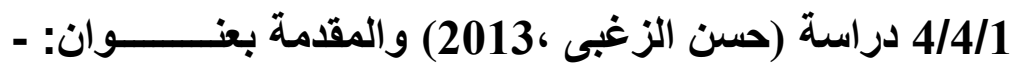
تحليل العلاقة بين رأس المال الفكرى وإدارة الجودة الثاملة وانعكاسها على الابتكار الهـف من الاراسة

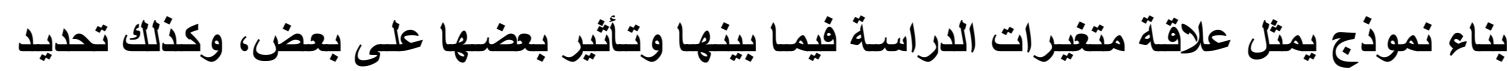

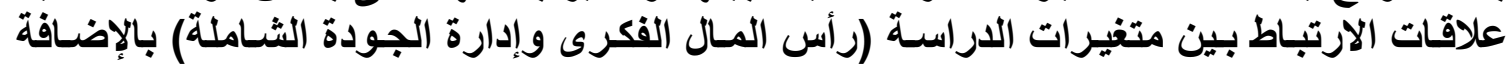
لتحديد أثر علاقة رأس المال الفكرى وإدارة الجودة الثاملة) فى تحقيق الابتكار. ـ أهم النتائج التي توصلت إليها الدراسة:

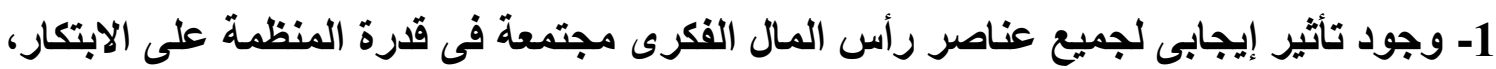

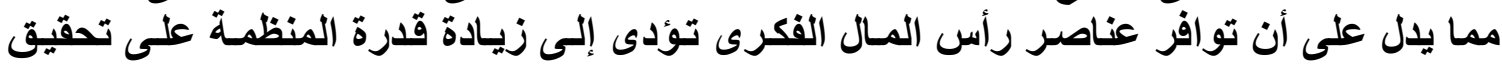
الإبتكار.

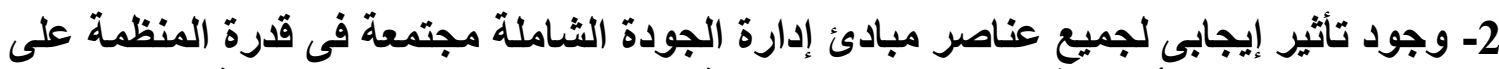

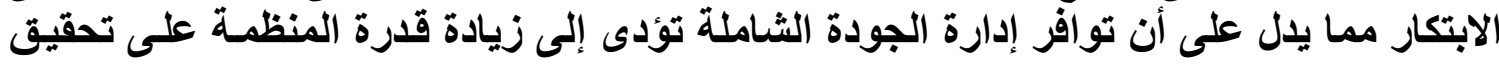

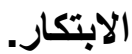

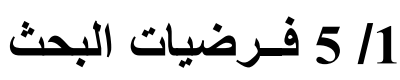
تقوم هذه الدراسة على فرضية رئيسية وعدد من الفرضيات الفرعية كما يلى: 


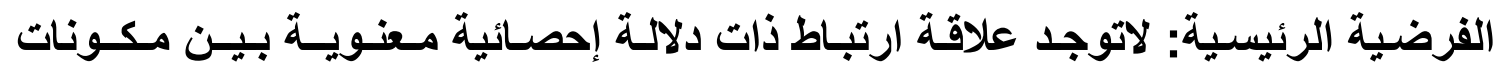

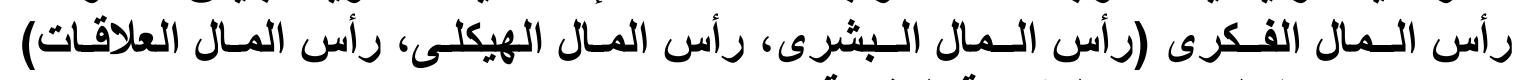
وتحسين جودة الخدمـات الملاحية المقدمة.

ويشتق من الفرضية الرئيسية ثلاثة فرضيات فرعية التالية:

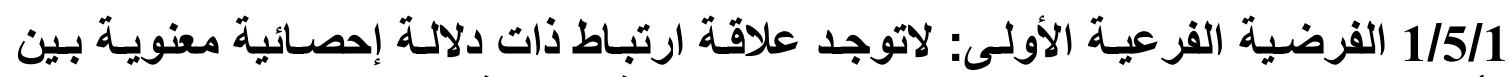
رأس المال البشرى و تحسين جودة الخدمـات الملاحية المقدمة. ويتم التعبير عن هذه الفرضية إحصائيا بالثكل التالى:

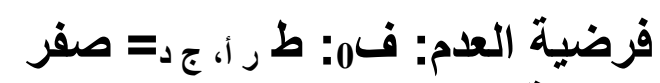

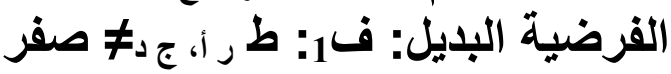

رالم/1/ الفرضية الفرعية الثانية: لاتوجد علاقة ارتباط ذات دلالـة إحصائية معنويـة بين رأس المال الهيكلى و تحسين جودة الخدمـات الملاحية المقدمة. ويتم التعبير عن هذه الفرضية إحصائياً بالثكل التالى:

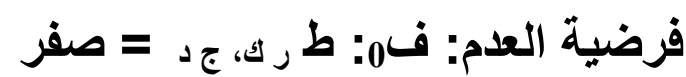

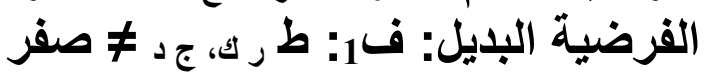

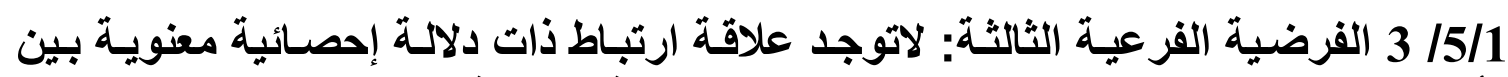
رأس المال العلاقات و تحسين جودة الخدمسات الملاحية المقدمة. ويتم التعبير عن هذه الفرضية إحصائياً بالثكل التالى:

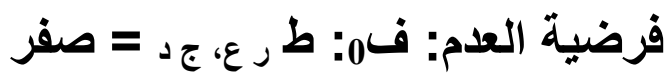

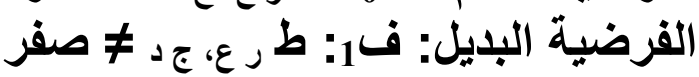

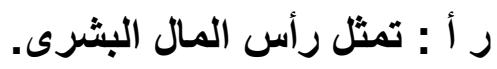
حيث ج د : تمثل جودة الخدمة. رع : تمثل رأس المال العلاقات. رك: تمثل رأس المال الهيكلى. 


$$
\begin{aligned}
& \text { ثُاتياً: رأس المـــال الفكــىى: } \\
& \text { 1/2 مفهـــوم رأس المـــال الفكــىى: }
\end{aligned}
$$

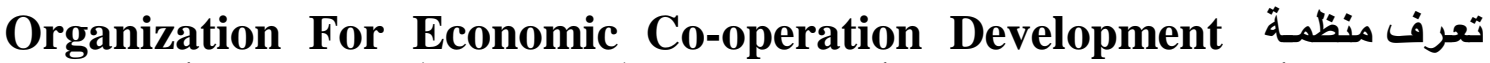

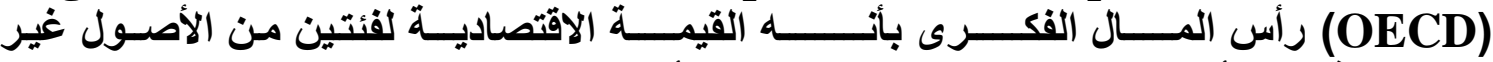

الملـموسـة هى رأس المال التنظيمى (الـهيكلى) ورأس الـمال البشرى (OECD, 1999).

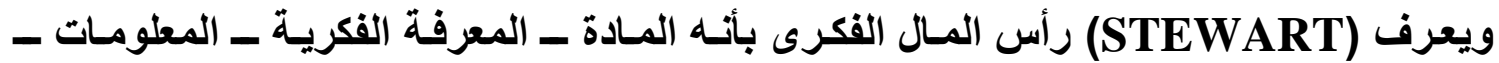

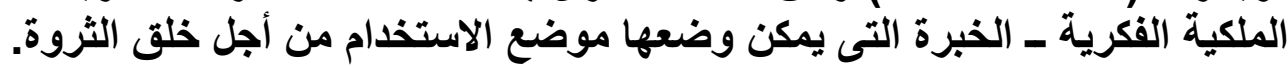

بالإضـافة لذلك، يعبر STEWART عن رأس المـال الفكرى بأنسه مبنى على أسـاس المعرفة

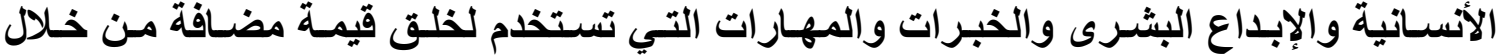

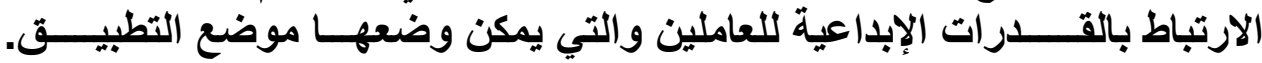
كما يوضـح (Thomas A.Stewart, 1997) أن رأس المسال الفكرى هو الطاقـات المعرفية الفية

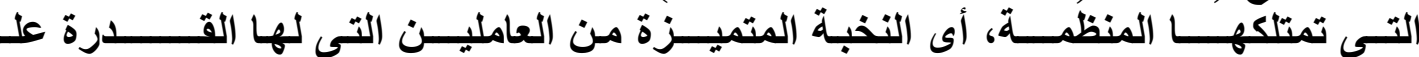

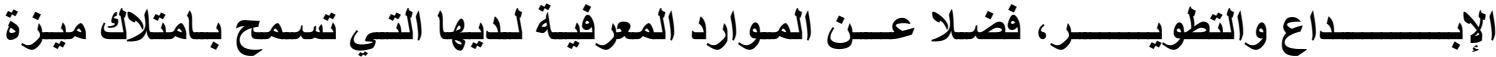

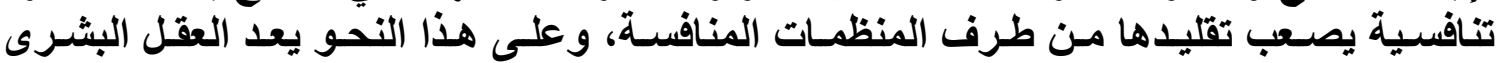

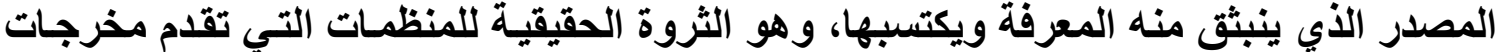

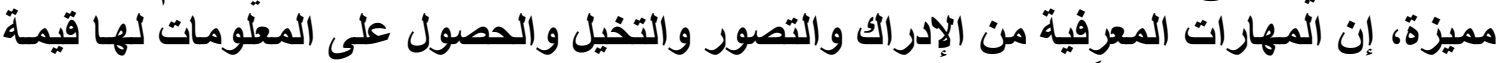

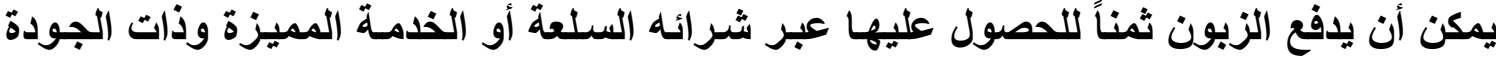

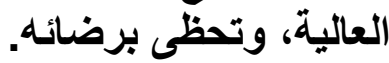

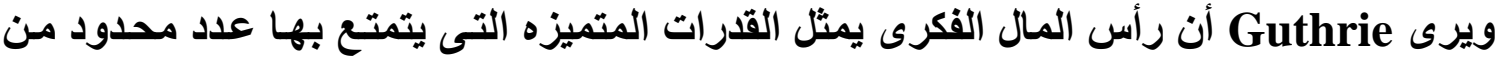

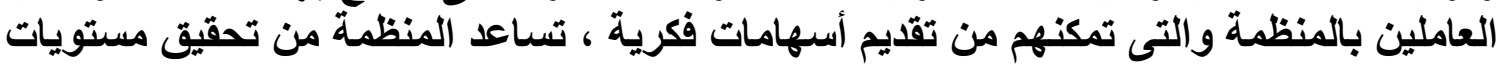
أداء عالية الجودة مقارنة بالمنظمات المماثلة (Guthrie.J, 2001). ويرىTomas أن رأس المال الفكرى هو الموهبة والمعرفة التقتية والخبرات والتعليم المتراكم في العنصر البشرى التى يمكن تحويلها إلى قيمة مضافة للمنظمة ( Tomas, and Kenneth, .2004 2/2

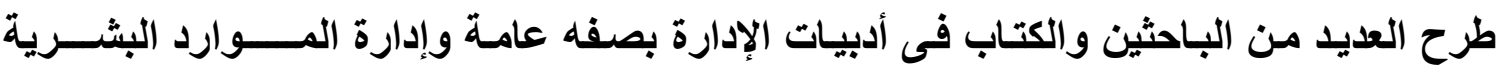

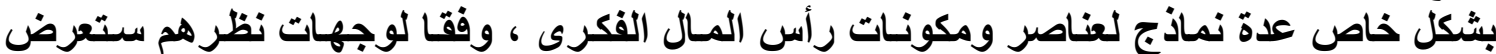

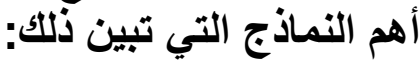


1/2/1 تعد الأفكار التي قدمها (Brooking, 2002)، في عناصر رأس المـال الفكري ذات أثر الثر الثري كبير في هذا المجال، وأقترح المكونات الأربعة الآتية لرأس المال الفكري:

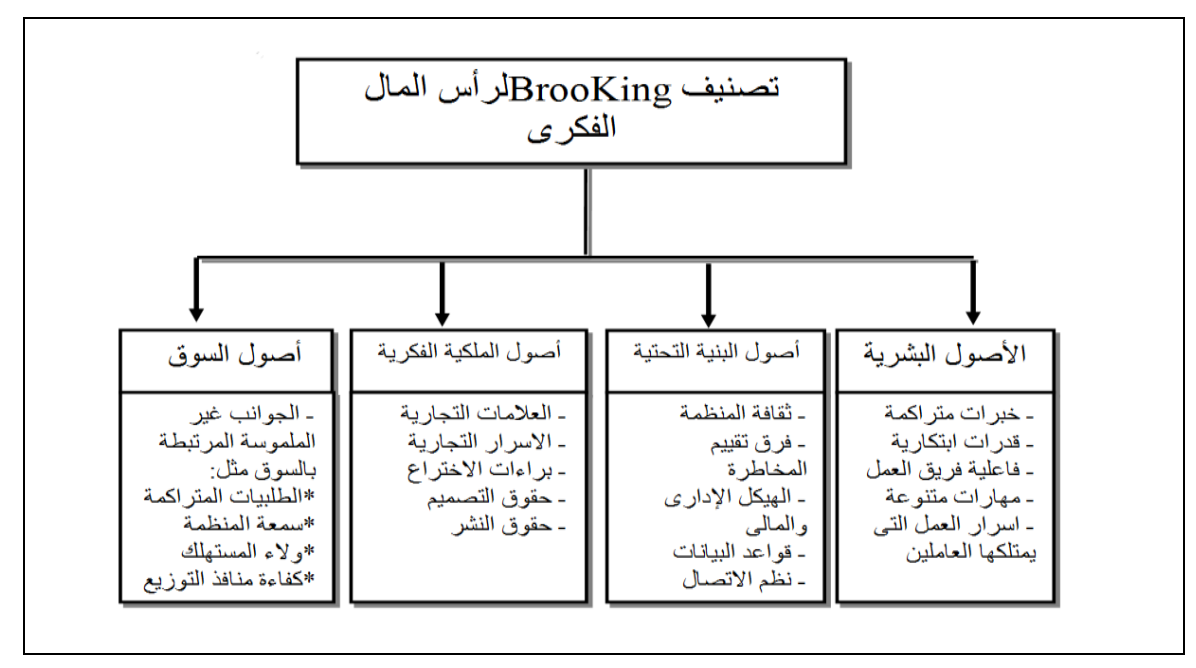

BrooKing الثكل رقم (1) تصنيف رأس المال الفكرى وفقا

2/2/2 أما Stewart يرى بأن رأس المال الفكرى يتضمن ثُلاث عناصر تثتفاعل كل منهمـا معا

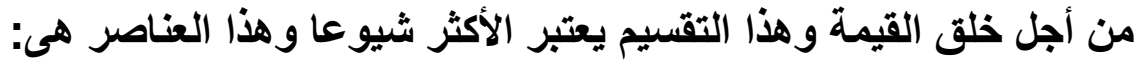

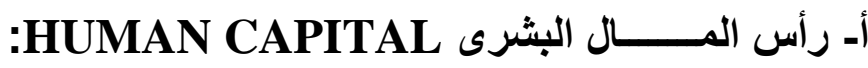

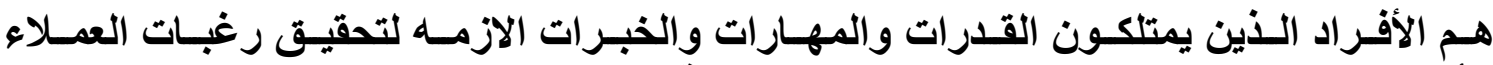

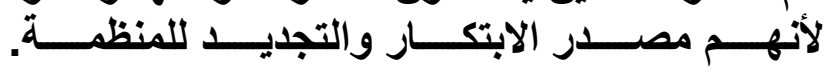

ب- رأس المـــــال الهيكلى STRUCTURAL CAPITAL:

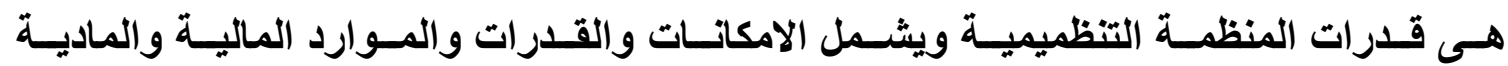

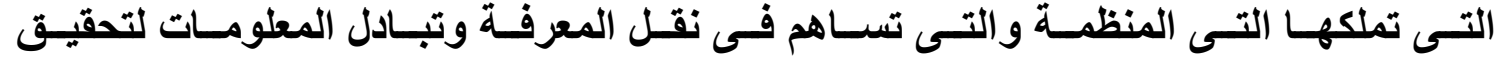

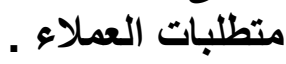

ج- رأس المـــــال الزبونـــ CUSTOMER CAPITAL:

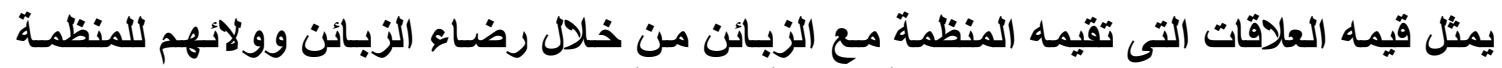

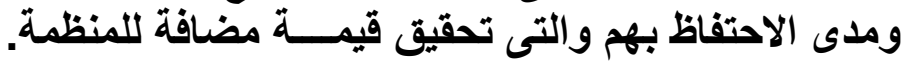




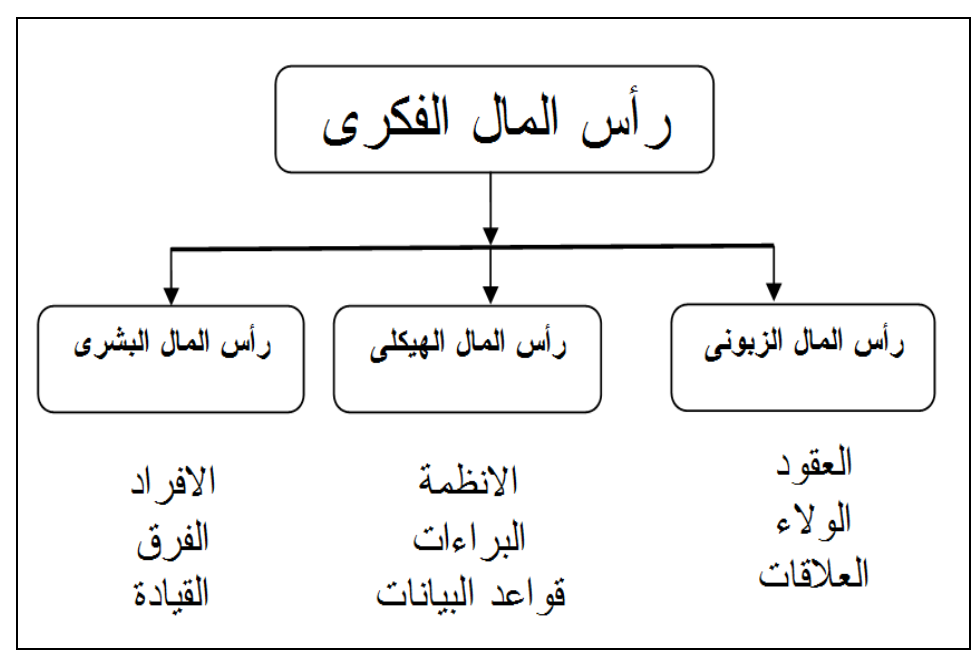

الثكل رقم (2) تصنيف رأس المال الفكرى وفقا Stewart (نجم عبود، 2008)

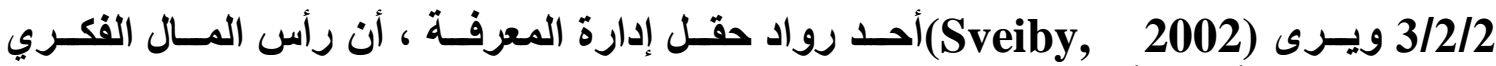
يتكون من ثلاث أجزاء أساسيه كما موضح بالجدول الاتى:

Sveiby الجدول رقم (1) مكونات رأس المال الفكرى وفقاً لـ

\begin{tabular}{|c|c|c|}
\hline تثمل القدرات، المعرفة ،المهارات، الخبرات. & كفاءة العنصر البشرى & تصنيف \\
\hline 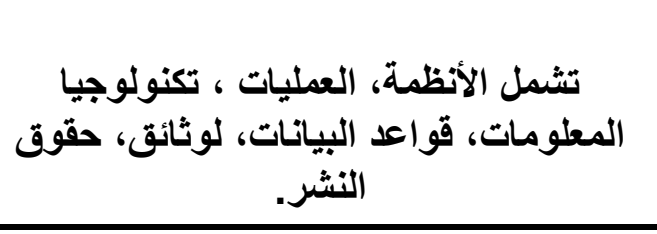 & $\begin{array}{l}\text { الهيكل الاخلىى } \\
\text { Internal } \\
\text { Structure }\end{array}$ & $\begin{array}{l}\text { Sveiby } \\
\text { لرأس المال الفكرى }\end{array}$ \\
\hline الموردين،المناقسون وكلة مي مايتعلقى بالتميز & الهيكل الخارجى & \\
\hline
\end{tabular}


من الجدول السابق ، يتبين اهتمام Sveiby بالعاملين في المنظمة وبخبراتهم، وركز كثيراً على ولئ

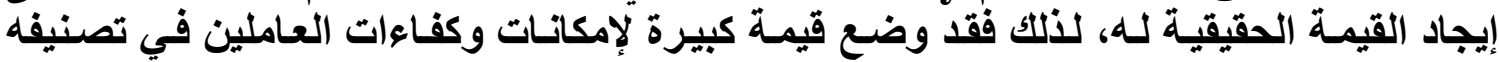

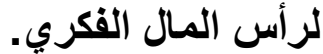

*وفى أطار ما سابق ذكره، من تعريفات وعناصر لمكونات رأس المـال الفكرى فإن الباحث يرى

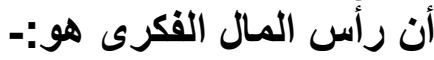

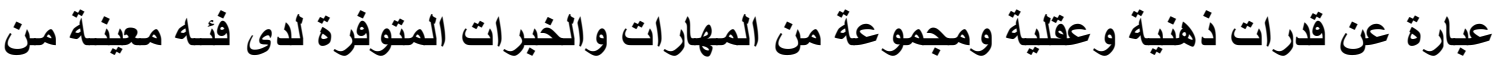

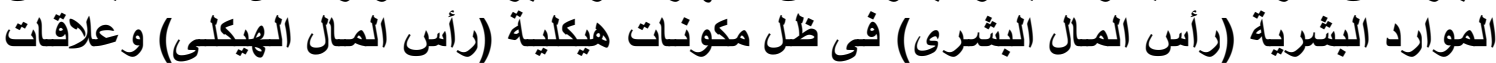

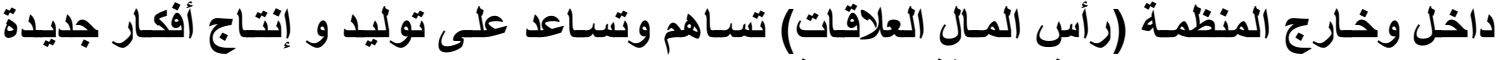
ومبتكرة تؤدى إلى خلق قيمة مضافة للمنطمة المناف

«ما يرى الباحث إلى أن رأس المال الفكرى يتكون من العناصر التالية:-

أ- رأس المــــــال البشرى Human Capital هم الأفراد الذين يمتلكون القدرة الفكرية والمعرفة والمهارات والخبرات الازمه لتحـويل المعرفة

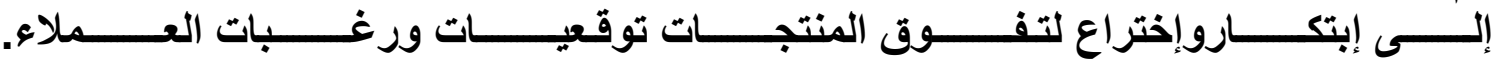

ب- رأس المـــــال الهيكلى Stuructural Capital: (البيئة|لا(خلية)

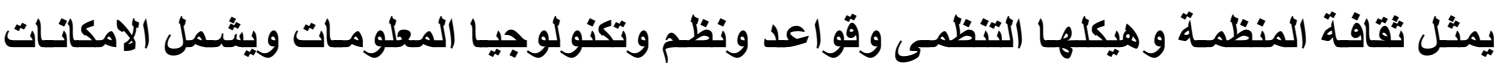
والقدرات المالية والمادية التى تملكها التى المنظمة والتى تساهم فى نقل وتبادل المعلومات التئل

ج- رأس المال العلاقات Realational Capital (البيئة الخارجية المباشرة)

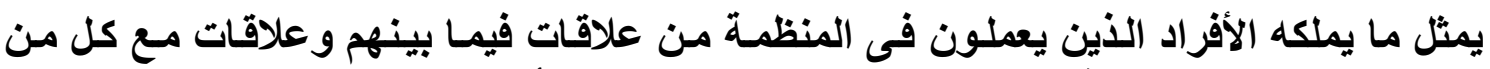

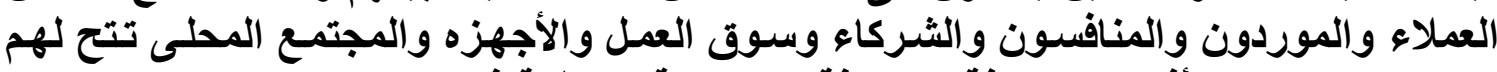
تبادل المعلومات والأفكار والمعرفة بالإضافة إلى سمعة المنظمة في سوق ولى العمل. ويرى الباحث أن رأس المال البشرى المتمثل في العنصر البشرى هو أساس رأس المسال الفكرى

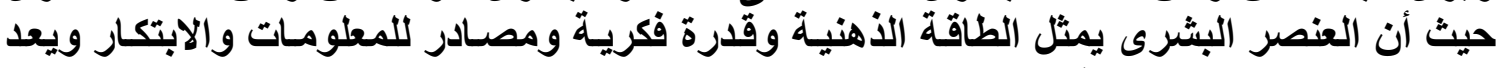
المسئول عن نتائج المنظمة وسمعتها. 


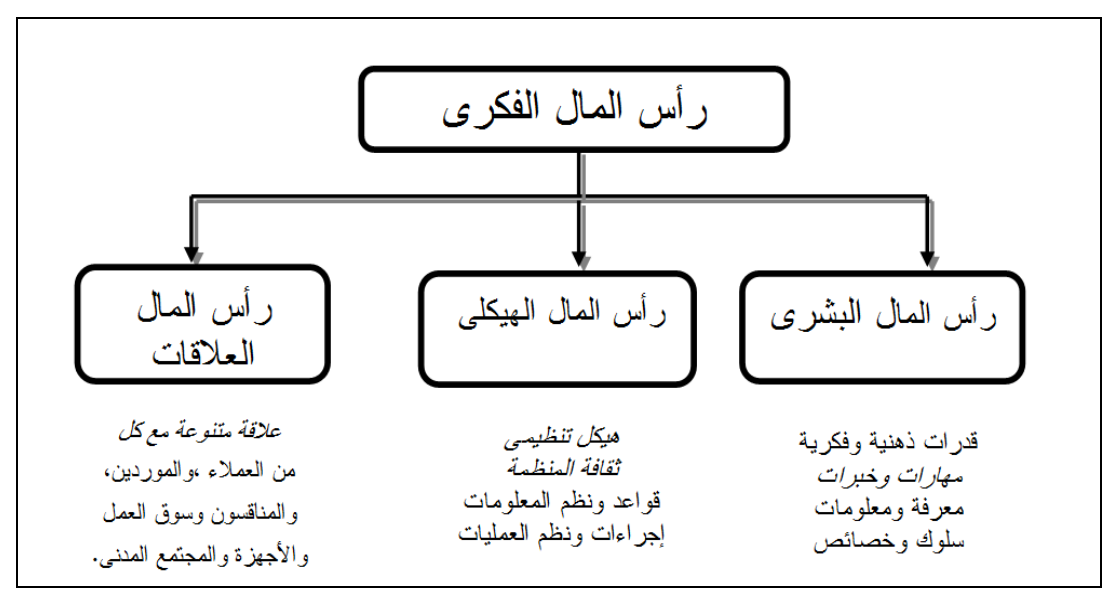

الثكل رقم (3) عناصررأس المال الفكرى 
3/2 - 3/2 أبعاد رأس المال الفكرى:

من خلال الأدبيات الفكريـة عن آراء ووجهات نظر الكتاب والبـاحثين عن موضوع رأس المـال

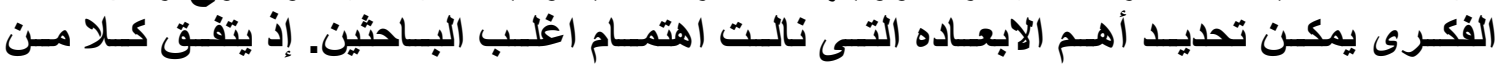

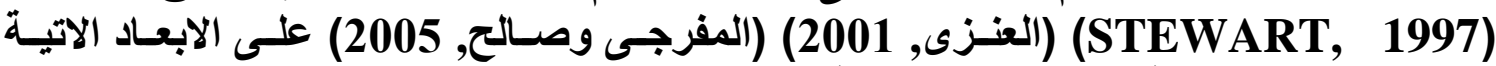
(الاستقطاب ؛ الصناعة ؛ التنشيط؛ المحافظة ؛الاهتمـام بالمستفيدين ؛ التدريب والتطوير) ويمكن تعريف كل بعد من هذه الابعاد وكما يأتى:

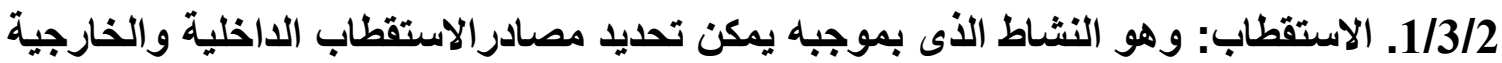
للأفراد المؤهلين بهاف جذبها واختيار المرشحين الملائمين للوظائف الشاغرة فى المنظمة.

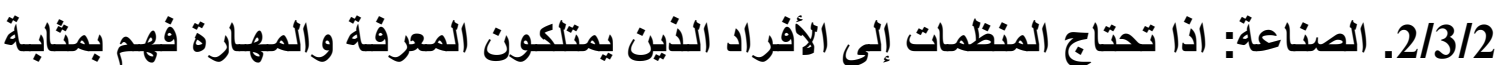

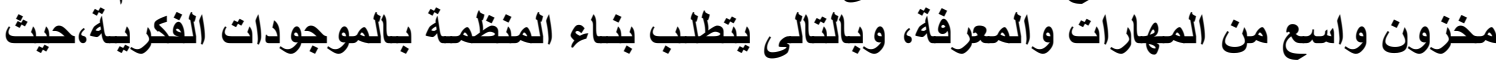

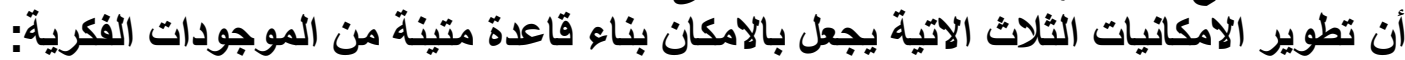

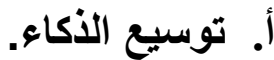
ب. ب. ممارسة التكامل في العلاقات بالتوحيد في الأفكار والأعمال.

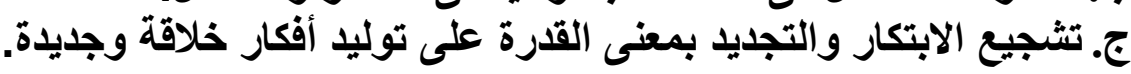

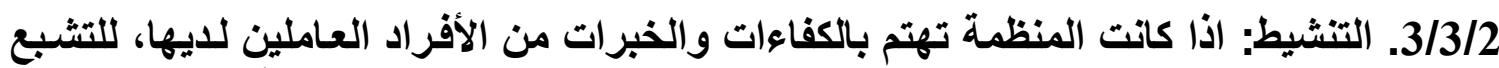

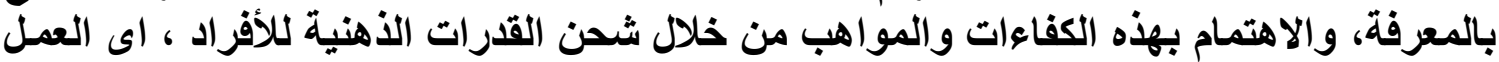

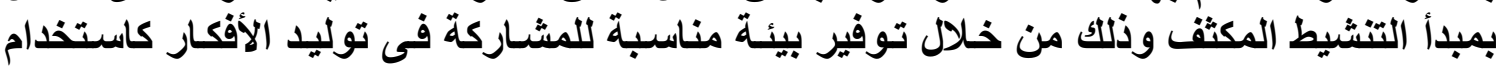
أساليب ذهنية مثل العصف الذهنى وأساليب الفكرى الجماعى وأساليب الاجتماعات المرنئه

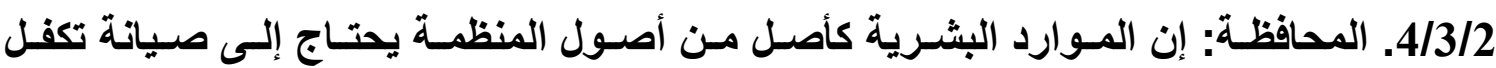

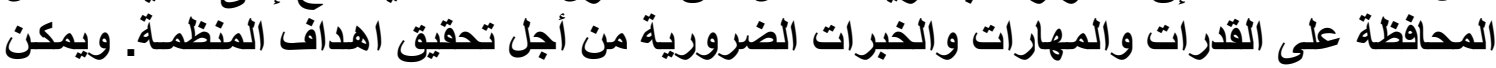

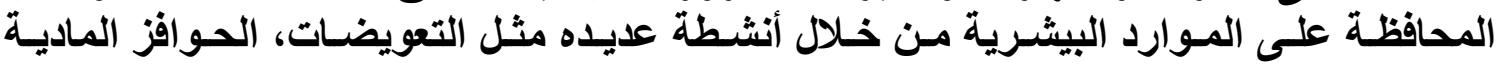

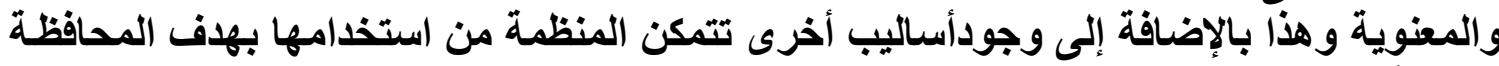
على رأس مالها الفكرى والتصدى للتقادم التنظيمى.

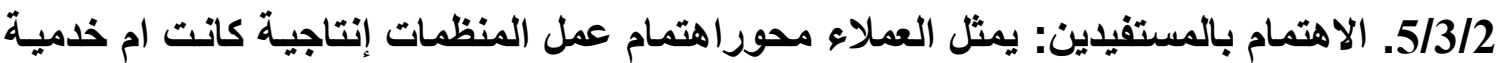

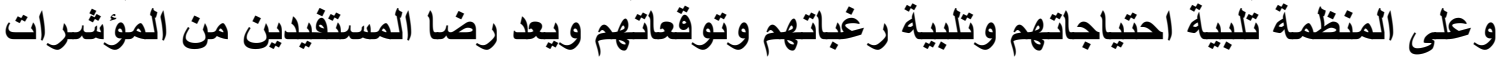

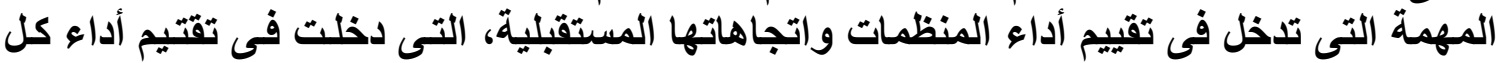
منظمة وخاصة تقنية المعلومات والاتصاتلات ، لاسيمات واتجا فلى ظل الثورة المعلوماتية.

6/3/2. التدريب والتطوير: يعمل التدريب على ثقل المهارات التى يحتاجها العاملين لرفع كفاءهاه

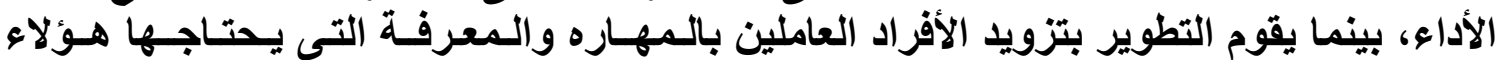

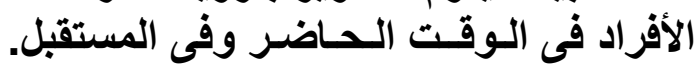


أن كل من التدريب والتظوير واكتسـاب المهارات والخبرات والمعرفة، كل يسـاعد على التعديل

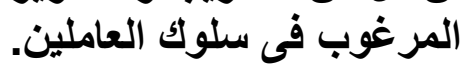
4/2 أساليب تطوير وتتمية رأس المال الفكرى:

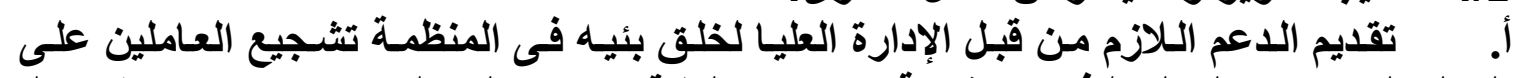

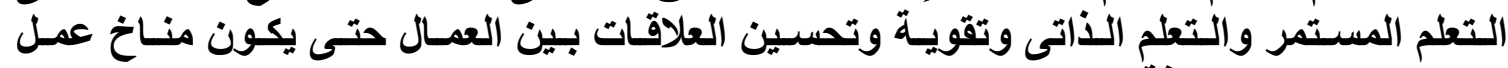
محفز على تبادل المعرفة والخبر الخبرات. ب.أن توفير الإدارة العليا الدعم والامكانيات المادية اللازمة للخبراء والمبدعين لستخراج طاقتهم

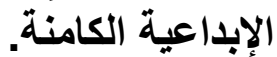

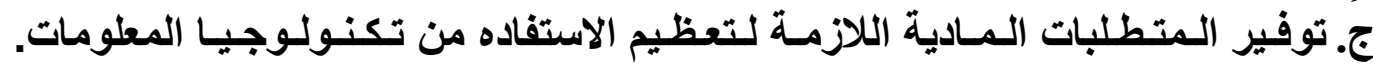
د. زيادة الأنفاق من أجل إكتساب العاملين مهارات وخبرات متميزة من بئيات التعلم فى المنظمات

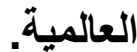
ه. إتخاذ قرارات سريعة وفورية بمكافأة العاملين على العمل الإبداعى الذى يتقرر الأخذ بـه مـع

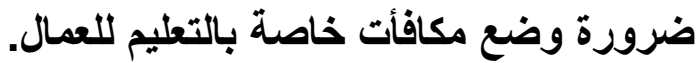

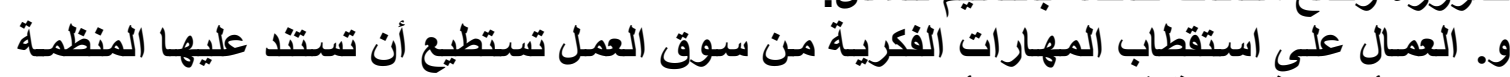
كقدرات أساسية مهمة في تكوين رأس المال المال الفكرى.

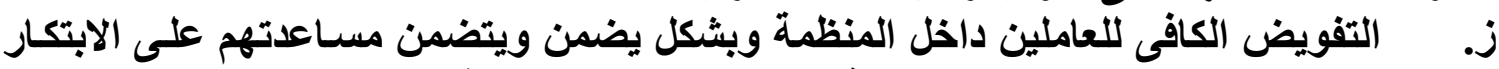

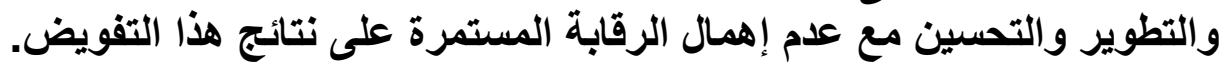

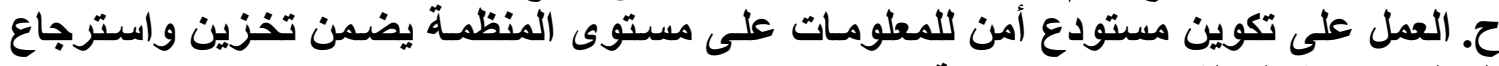

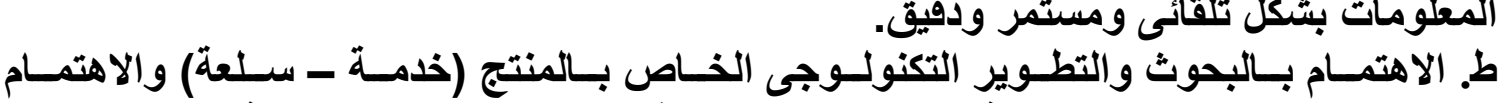

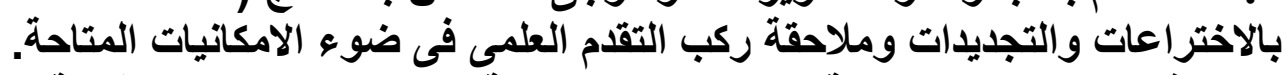

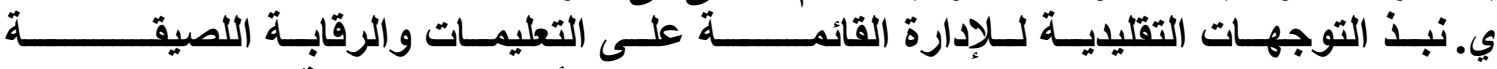

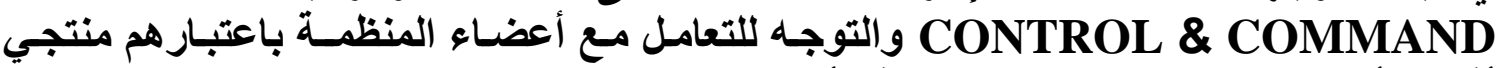

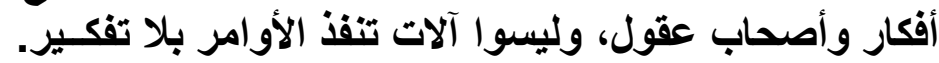

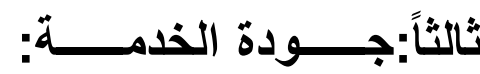
1/3 مفهوم جــــودة الخدمــــة: يمكن اعتبار الخدمة أنها بعض الاشياء التى تتتج وتستهلتك بثكل متزامن (و لكن يمكن بعد الحصول عليها الثعوربنتائجها او تأثيرها. أما الباحثون (Voss \& Norman, 1985) يعرفون الخدمة بأنها تفاعل اجتماعى بين مجهز الخذمة والزبون، ويهذف هذا التفاعل إلى تحقيق الكفاءة لكليهما. 


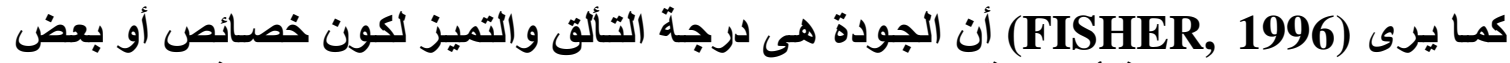

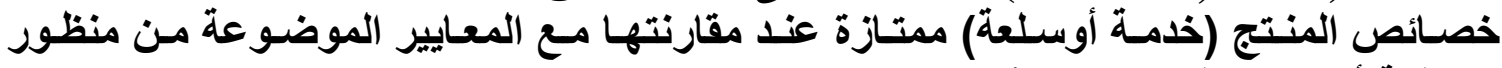

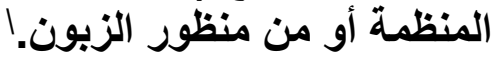

ويرى (PARASURAMAN, 1985) أن مفهوم رضـا العميل على أنها "حكم عام أو اتجاه

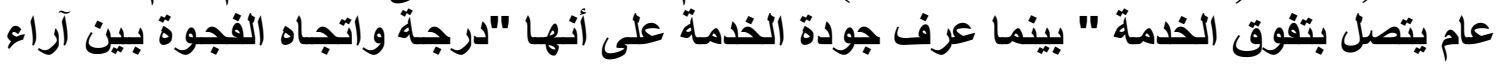

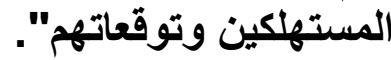
ولقد وصف (KWAN, 1996) مفهوم الجودة فى خمسة أتجاهات هى:

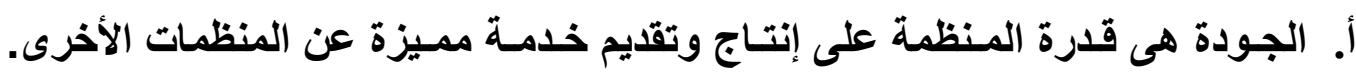

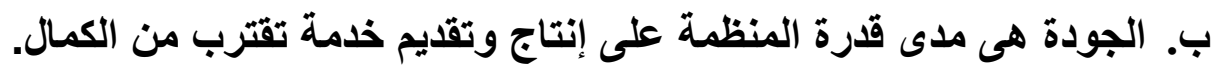

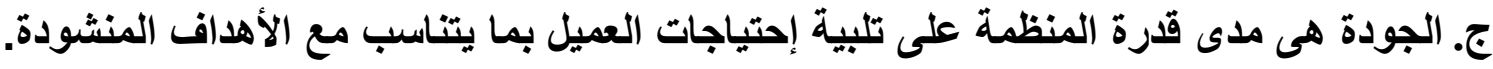

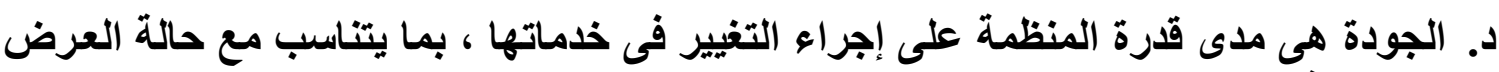
و والطلب فى السوق.

ه. الجودة هى مدى قدرة المنظمة على تحقيق أرباح مالية أكثر. 2/3 أهمية تطبيق الجودة فى المنظمة:

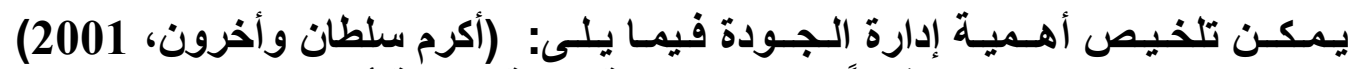

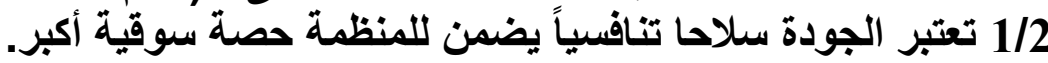

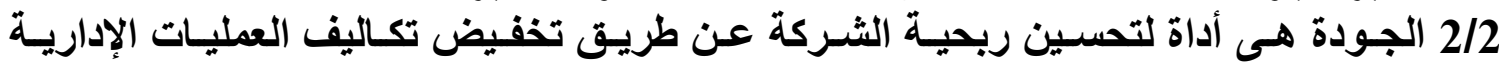

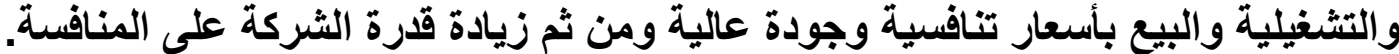

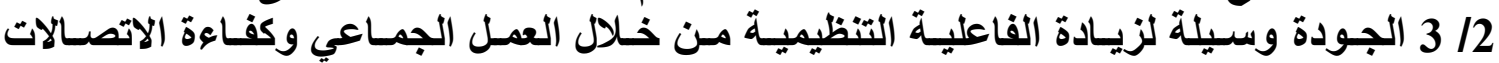

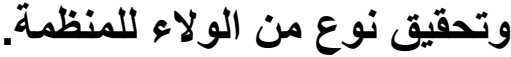

4/2 الجودة تسعى لتحقيق رضا الزبائن عن طريق التركيز على حاجاتهم ورغباتهم.

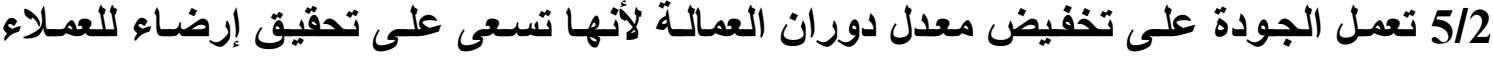
سوى عملاء داخليون أو عملاء الخارجيض تعليون. 6/2 تعمل الجودة على جذب عملاء جداء لديهم الرغبة في الحصول على خدمة متميزة. 3/3 قياس جودة الذدمة وأبعاد جودة الخدمة: لقد توصل (Parasuraman,1985) أن هنـاك عشـرة معسيير أساسية لتقييم جودة الخدمسة المقدمة وفقا لإدارك العميل وهي ثابتة لكل الخذمات المقامة وهي: 1/3/3 الاعتماديـة Reliability والتي تعنى درجـة الانسياق فى أداء الخدمسة وتقديمها بثكل وفيل

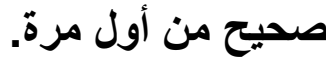


2/3/3 درجـة الاستجابة Responsiveness والتـى تثبر إلى سرعة استجابة مقدمى الخدمـة

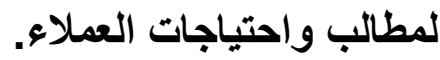

3/3/3 الجدارة Competence والتي تعنى امتلاك الأفراد مقدمى الخدمة للقدرات التى تمكنهم من تقديم خدمة متميزة للعملاء.

4/3/3 الأمان Security وتعنى المام العاملين بمهام وظائفهم وبشكل يمكنهم من تقديم خدمـة خالية من أى نوع من المخاطر. 5/3/3 الجوانب المادية الملموسية Tangible ونثـمل المظهر الخـارجى للأفراد والمعدات و

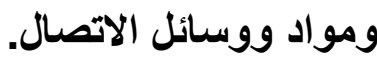

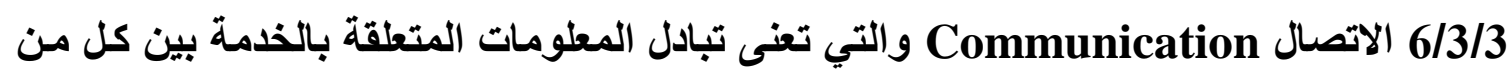
مقدمى الخدمة و العملاء بشكل سهل ومبسط. 7/3/3 المصداقية Credibility وتعنى توافر درجة عالية من الثقة فى مقدمى الخدمة من خلال مراعاة مصالح واحتياجات العملاء. 8/3/3 إمكانية الوصول Accessibility والتى تثثير إلى سـهولة الوصول إلى مقدمى الخدمـة

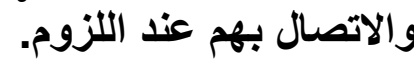

9/3/3 التعـاطف Empathy عن طريق بـل كافـة الجهود للتعريف على احتياجـات العملاء ،

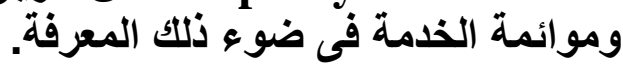

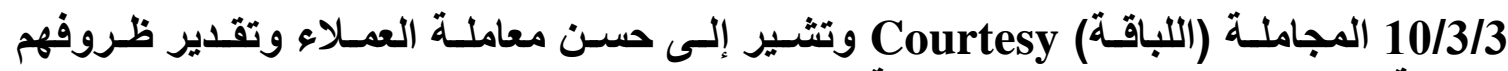
الخاصة والاحترام والود بين مقدم الخدمة والزيون

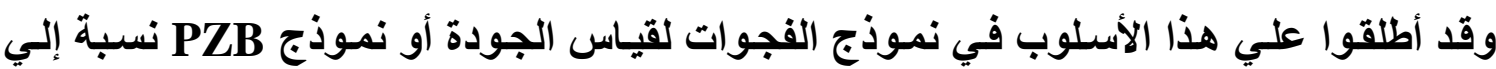
الحروف الأولي لمكتشفيه (Parasuraman , Zeithaml \& Berry).

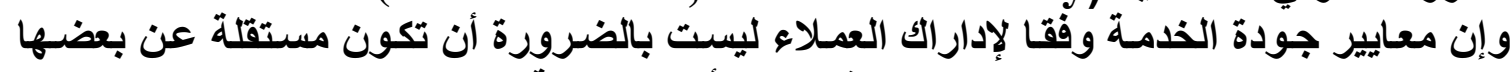

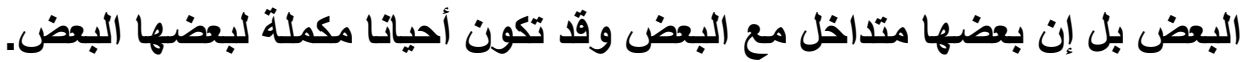

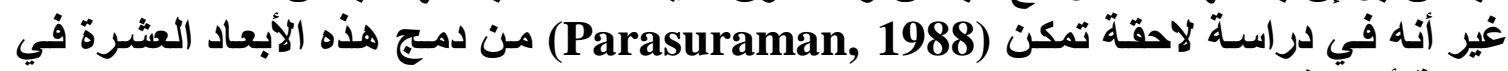

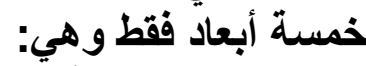

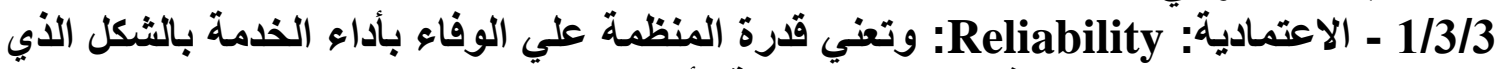

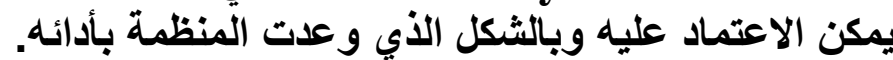

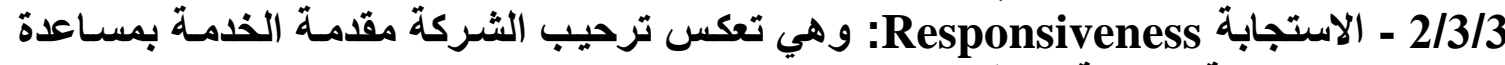
العملاء و الاستجابة الفورية لمتطلباتهه. 3/3/3 - التعاطف Empathy: وهو يعكس مدي التفاني والاهتمام الموجه لكل عميل من عملاء المنظمة مقدمة الخدمة. 
4/3/3 - الأمان Assurance: وهو يعكس مدي قدرة العاملين في المنظمة مقدمة الخدمة علي بث الثقة والأمان في نفوس العملاء عذد التعامل.

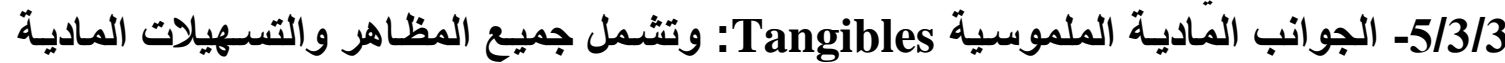

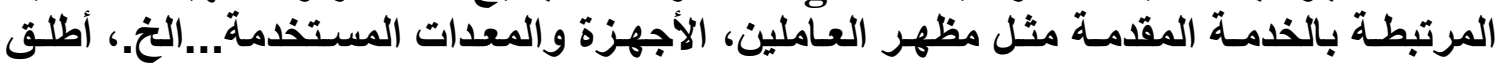
عليها نموذج جودة الخدمة كما موضح بالثكل مظئل رقم (4). (تيسير العجارمة، 2005)

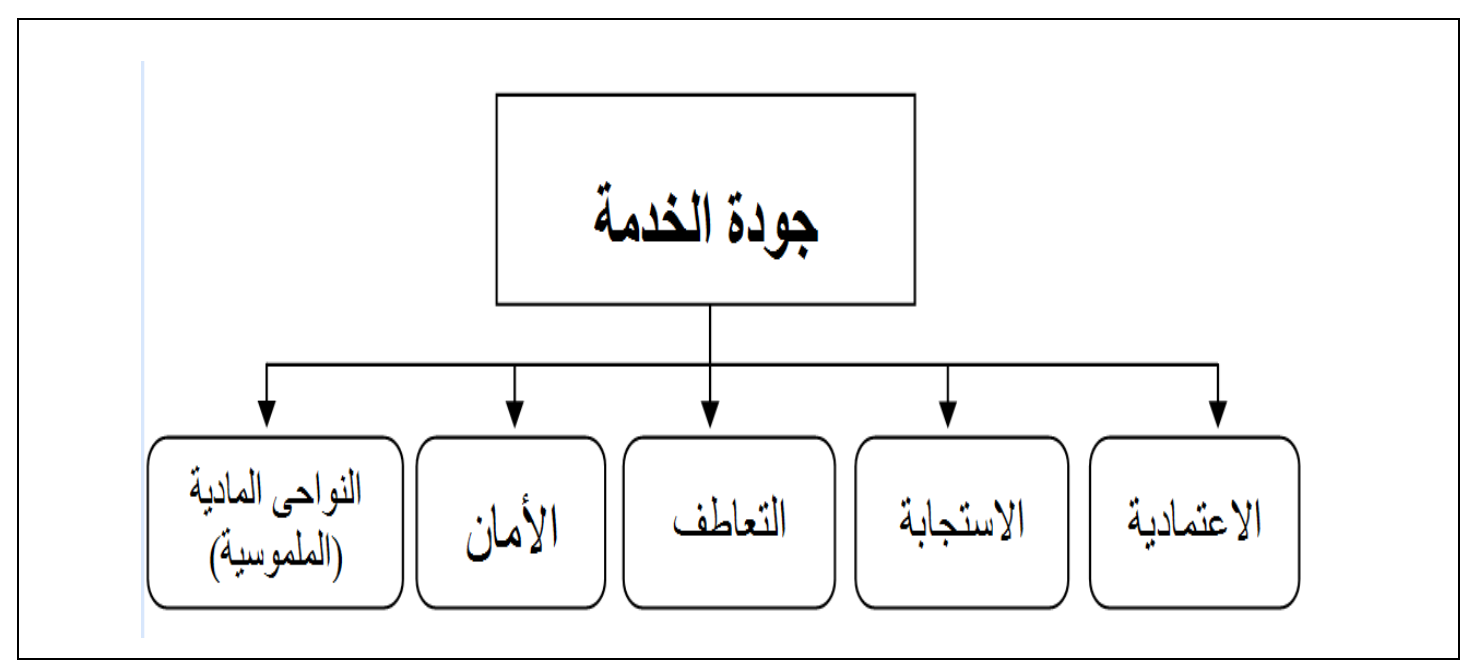

الثكل رقم (4) نموذج جودة الخدمة

رابعاً: الـعلاقة بين رأس المـال الفكرى وجـودة الخدمة: ويمكن بلـورة العلاقة بين رأس المسال الفكرى وجـودة الخدمـة مـن خـلال مبـادئ إدارة الجـودة

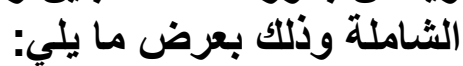

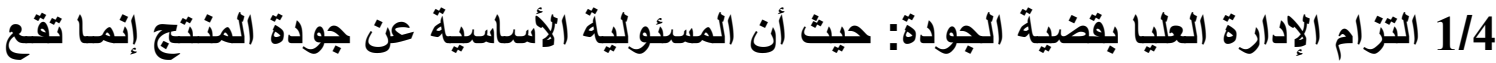

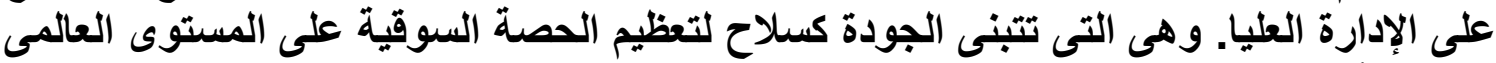
إلى مكافأة العاملين المتميزين فى مجال تحقيق الجودة الجئ

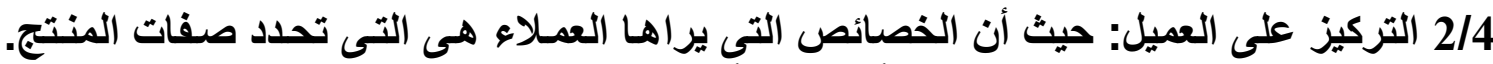
إن المتطلبات التى يريدها العملاء يجب أن تثكل أبعاد تصميم الجودة. 


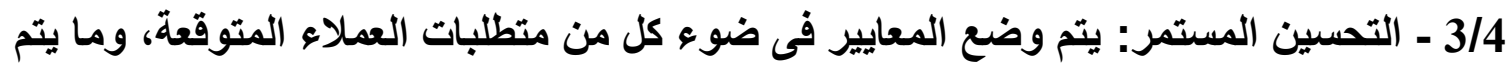

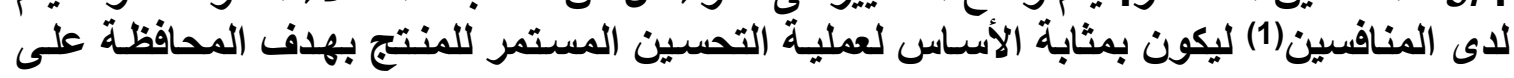

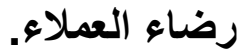

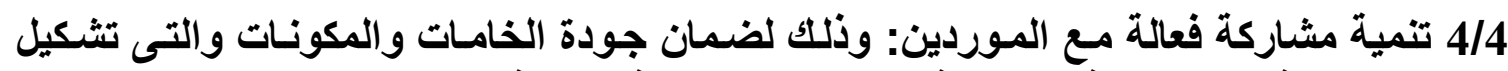

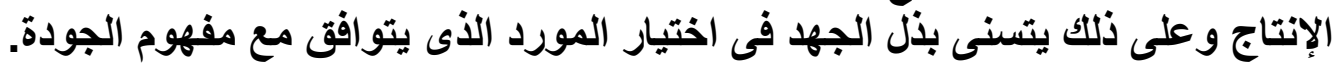

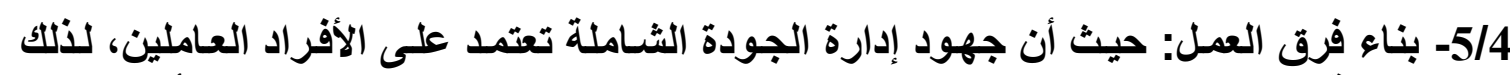

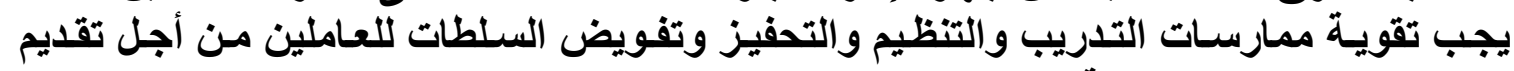
المنتج بمستوى جودة عالية.

6/4 خدمة العملاء: أصبحت من الأمور الحيوية التى تسهم فى تثكيل إدراك العميل للجودة.

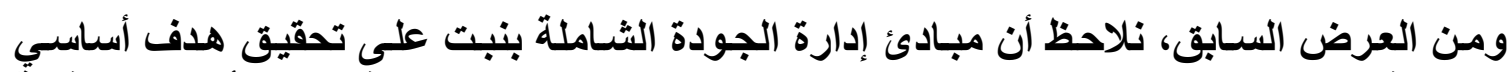

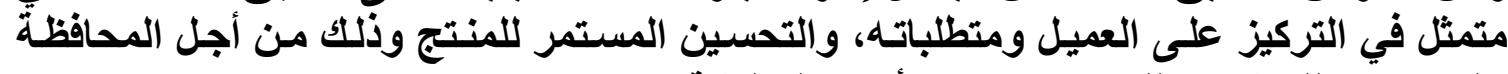

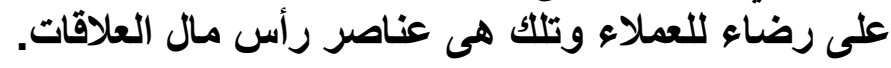
كما أنها ركزت على كفاءة الموارد البشرية على أساس التعليم والتدريب وتبادل الخبرة من من خلادل فرق العمل، وهذا يرتبط برأس مأل الموال البشرى.

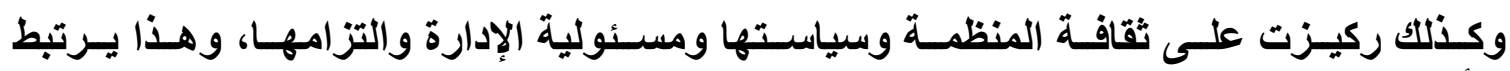

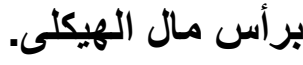

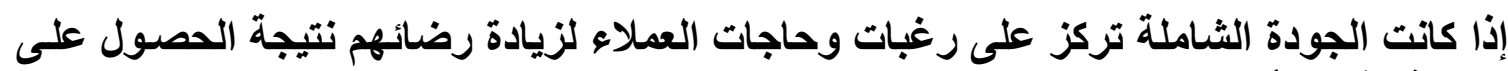

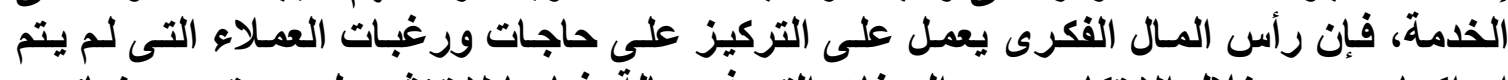

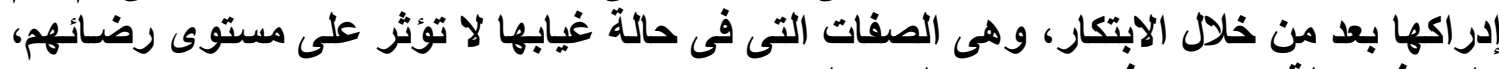

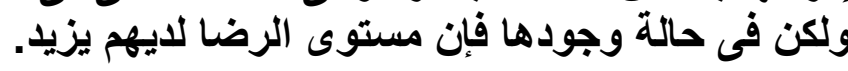

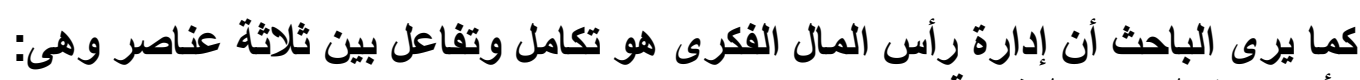

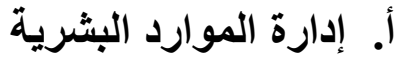

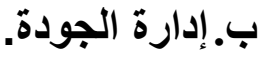
ج. إدارة البحوث والتطوير.

وهذه العناصر الثلاثة تكامل وتفاعل من أجل إنتـاج أفكار جديدة وخلاقهه تعمل على

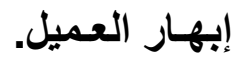


خامساً: اختبار الفرضيات وتفسير النتائج

$$
\text { 1/5 أساليب التحليل الإحصائى المستخدمة: }
$$

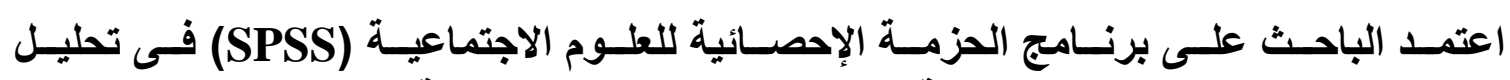

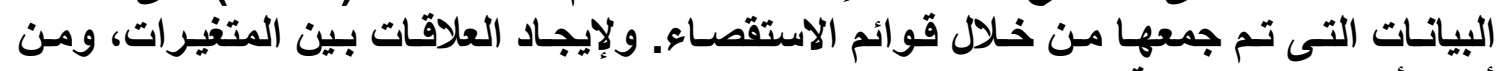

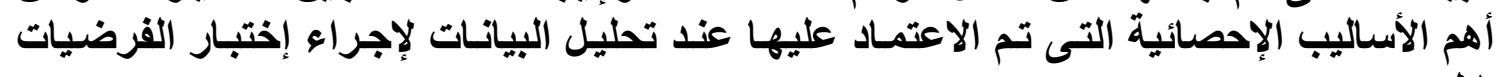
مايلى: الأسال

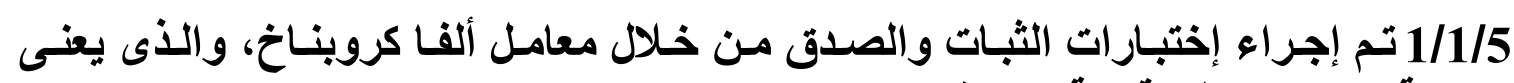
إمكانية الاعتماد على قائمة الاستقصاء البتاء والصداء.

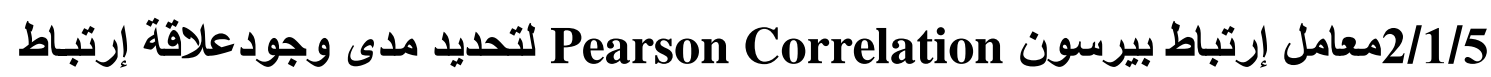
بين المتغيرات المستقلة والمتغير التابع.

3/1/5 معامل التحديد Coefficient Determination( التى يستطيع أن تفسرها المتغيرات المستقلة والمتغير التابع.

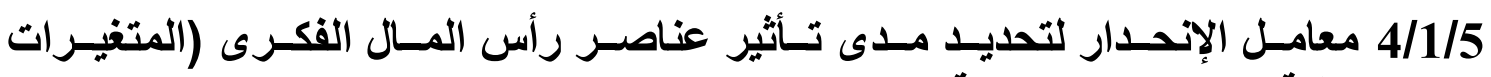
المستقلة) على جودة الإجدار لتحدية (المتغير التابع).

2/5 إختبار صدق وثبات الاستقصاء:

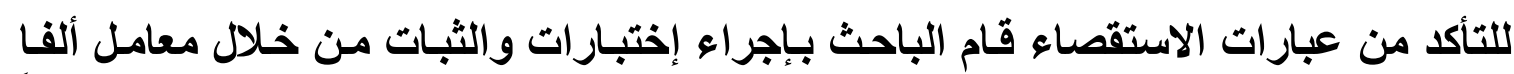

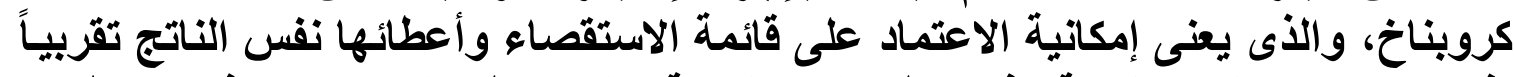

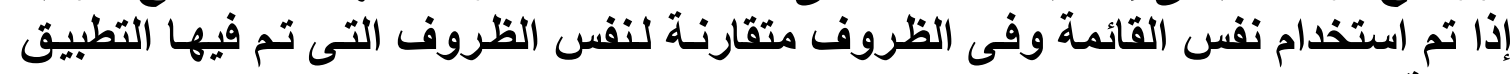
القائمة.

جدول رقم (2) نتائج إختبار ألفا كرونباخ

\begin{tabular}{|c|c|c|c|c|}
\hline \multicolumn{2}{|c|}{ معامل الصدق الذاتى } & \multicolumn{2}{|c|}{ معامل كرونباخ ألفا } & \multirow[b]{2}{*}{ العناصر } \\
\hline العملاء & العاملين & العملاء & العاملين & \\
\hline- & 0,96 & - & 0,926 & رأس المال البشرى \\
\hline$=$ & 0,941 & $=$ & 0,886 & رأس المال الهيكلى \\
\hline$=$ & 0,954 & $=$ & 0,936 & رأس المال العلاقات \\
\hline 0,976 & 0,981 & 0,952 & 0,94 & عناصرجودة الخدمة \\
\hline
\end{tabular}


*معامل الصدق الذاتى = الجذر التربيعى لمعامل الثبات ألفا كرونباخ

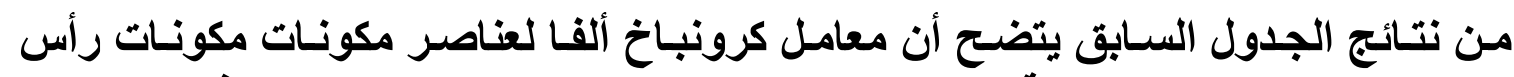

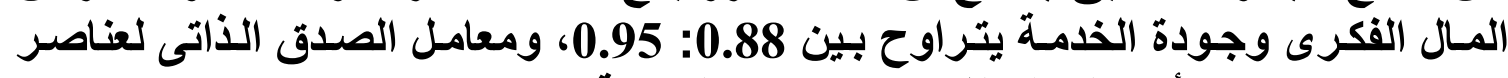

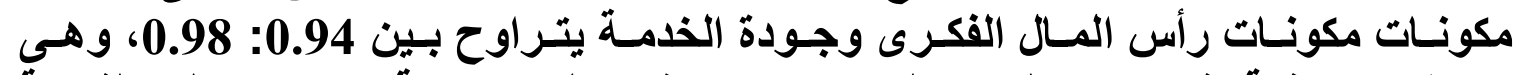

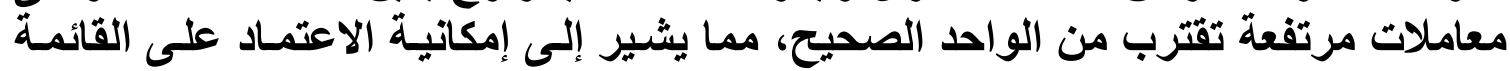

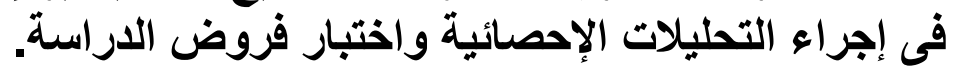
2/5 نتائج تحليل إختبار معامل الارتباط والإنحدار:

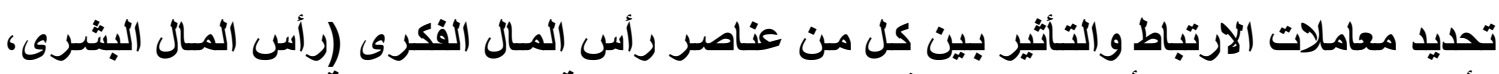

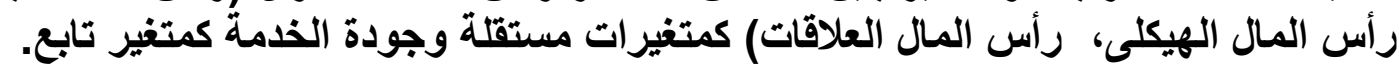

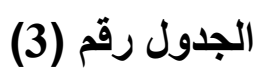

\begin{tabular}{|c|c|c|c|c|}
\hline مستوى معنوية & رأس المال العلاقات & رأس المال الهيكلى & رأس المال البشرى & البيان \\
\hline $\mathbf{0 , 0 0}$ & 0,779 & 0,657 & 0,619 & جودة الخدمً: \\
\hline
\end{tabular}

(4) الجدول رقم

معامل الارتباط الخطى المتعدد بين رأس المال الفكرى وجودة الخدمة

\begin{tabular}{|c|c|c|c|c|}
\hline \multicolumn{4}{|c|}{ رأس المال الفكرى } & \multirow[b]{2}{*}{ البيان } \\
\hline مستوىي & قيمة ف & التحدايد & الارتباط & \\
\hline $\mathbf{0 , 0 0}$ & 49,57 & 0,556 & $\mathbf{0 , 7 5 3}$ & جودة الخدمة \\
\hline
\end{tabular}

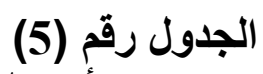

يوضيح معامل الإنحدار بين عناصر رأس المال الفكرى وجودة الخدمة 


\begin{tabular}{|c|c|c|c|}
\hline مستوى المعنوية & قيمة ت & معامل الإنحدار & البيان \\
\hline $\mathbf{0 , 0 4}$ & 2,180 & 0,260 & رأس المال البشرى \\
\hline $\mathbf{0 , 0 0}$ & 2,766 & 0,220 & رأس المال الهيكلى \\
\hline $\mathbf{0 , 0 0}$ & 2,586 & 0,520 & رأس مال العلاقات \\
\hline
\end{tabular}

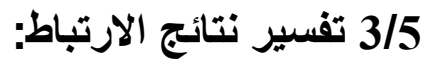
1/1 تثثير النتائج إلى وجود علاقة إرتباط خطى طردى متوسط ومعنوى بين رأس المال البشرى

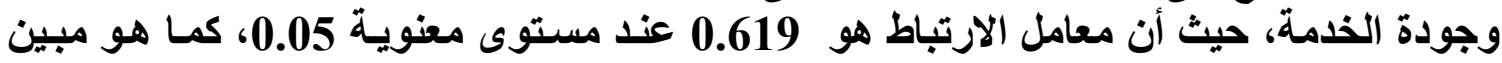

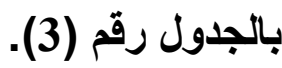

2/1 كما تثبير النتائج إلى وجود علاقة إرتباط خطى طردى متوسط ومعنوى بلين رأس المـال

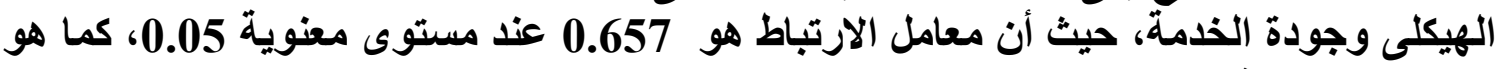

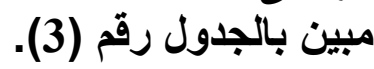
3/1 كما تثير النتائج إلى وجود علاقة إرتباط خطى طردى قوى قوى ومعنوى بين رأس مال العلاقات

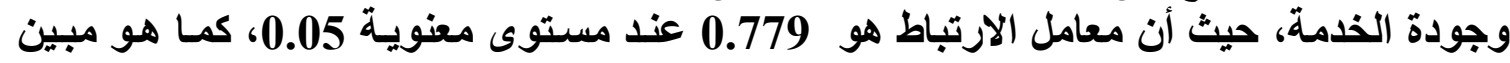

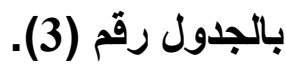

4/1 كما تثير النتائج إلى وجود علاقة إرتباط خطى طردى قوى ومعنى ومنوى بين عناصر رأس المال الفكرى مجتمعة وجودة الخدمة، حيث أن معامل الارتباط هو

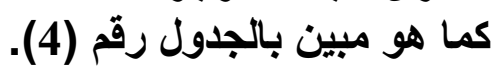
4/5 ت تفسير نتائج الإنحدار:

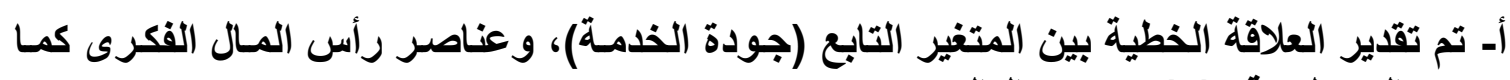
مبين بالجدول رقم (5)، وهى كالتالى:

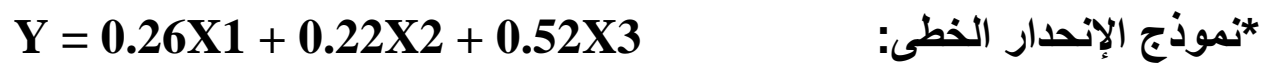
$0.753=$ = معامل الارتباط المتعدد لنموذج (R) 


$$
0.556=\left(\mathbf{R}^{2}\right) \text { معامل التحديد المتعدد لنموذج }
$$

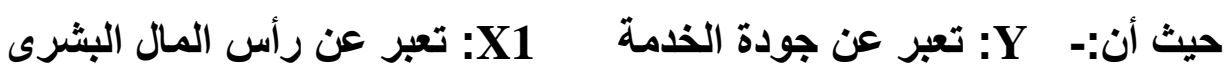

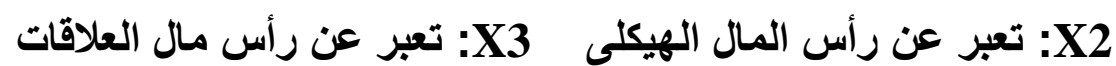

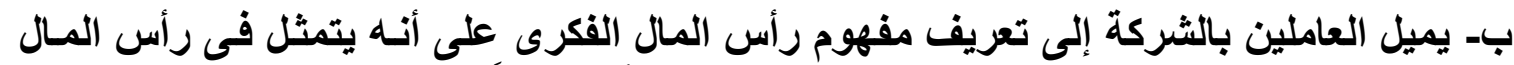

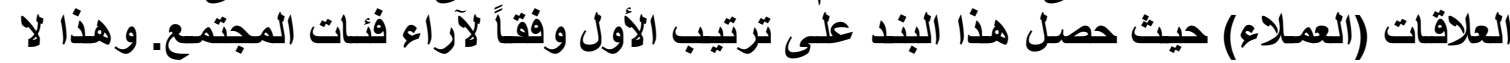

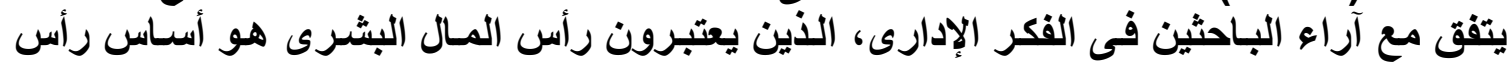

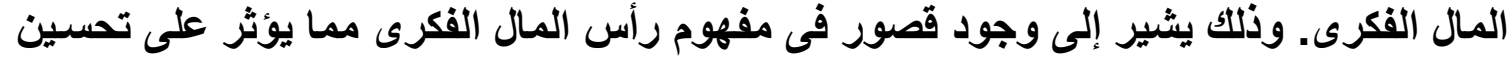
جودة الخدمة بالثركة الوطنية لخدمات الملاحة الجوية.

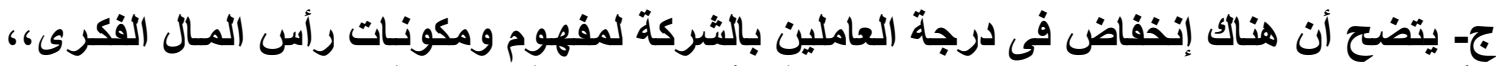
الأمر الذى يؤثر بثكل سلبى على إدارة وتنمية الأصول الفكرية بالثركة.

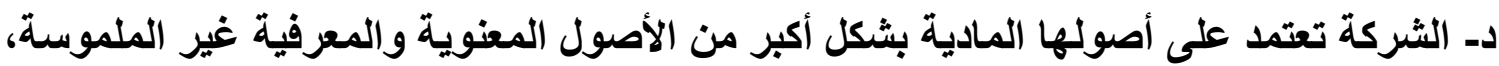

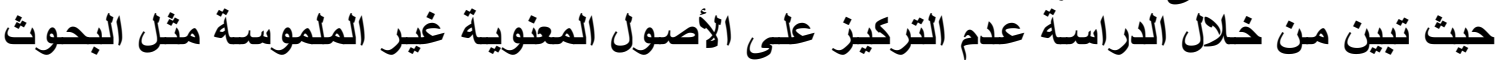
والتطوير وبراءات الاختراع والقدرات المعرفية والابتكارية للعاملين.

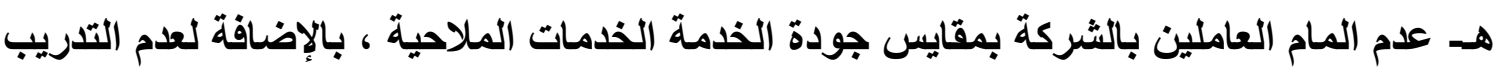
والمشاركة فى الندوة والمؤتمرات الدولية/الخاصة بجودة بلمة الخدمات الملاحية. 
أ. الاتتبـاه لأهمية إكتثـاف وتنميـة رأس المـال الفكرى (رأس المـال البشرى، رأس المـال

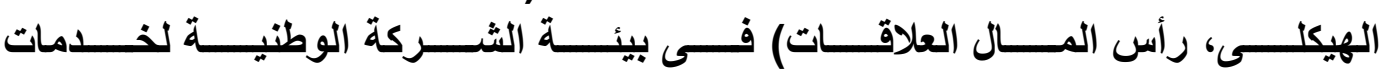

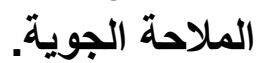

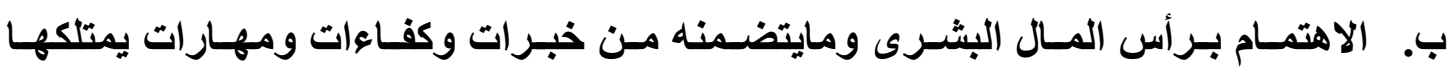

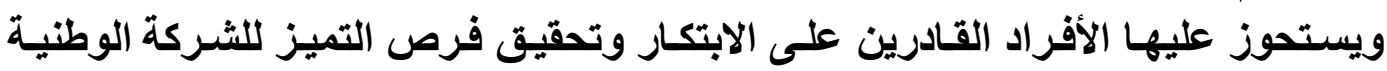

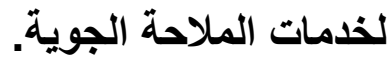

ج. الاهتمام برأس المال العلاقات لاى الثركة، لتحسين العلاقة مع العملاء ومايتضمنه و تلبية احتياجاتهم ورفع درجة رضائهم عن الخدمات المقامة لهم.

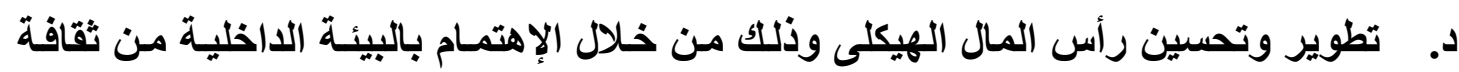

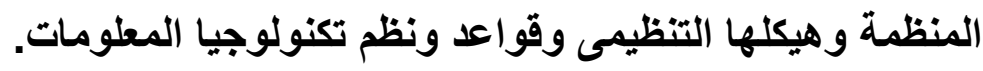

هـ تدريب العاملين بالثركة على برامج جودة الخدمات الملاحية وفقاً للمعايير والبرامج العالمية المتعلقة بهذا الثنأن.

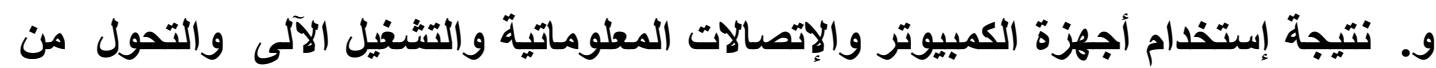

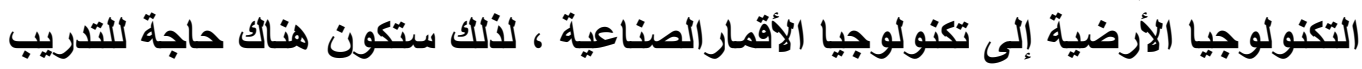

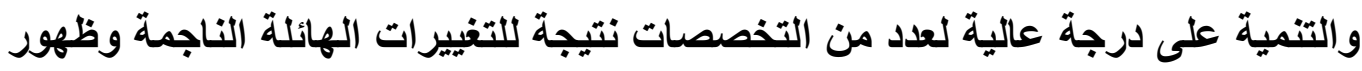
تخصصات جديدة فى مجال الملاحة والطيران نتيجة لإنخال نظم الملاحة الجوية العالمية

ز. دراسه الدخول فى التكتلات الجوية سواء كان مع الإتحاد الأوروبي لتحقيق التدريب

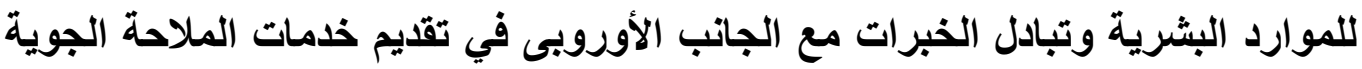

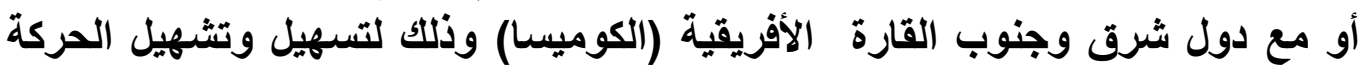
الجوية والتجارة فى القارة الأفريقية. 


\section{مراجع البحث

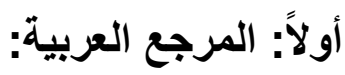

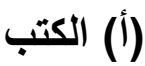

1- تيسير العجارمة ، التسويق المصرفى، عمان، دار الحامد، 2005. 2- راوية حسن، مدخل استراتيجى لتخطيط وتنمية الموارد البشرية، الدار الجامعية مصر،2005

3- سونيا محمد البكرى، إدارة الإنتاج والعمليات، الدار الجامعية، مصر، 2001.

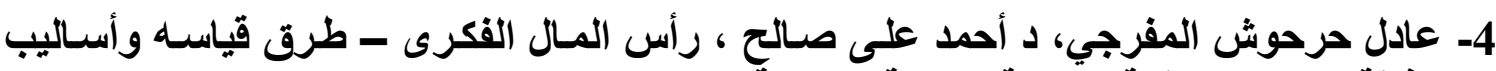
المحافظة عليه ،المنظمة العربية للتنمية الإدارية ، القاهرة ، 2003. 5- على السلمى ، إدارة الجودة الثـاملة ومتطلبات التأهيل للأيزو 9000، دار غريب، القداهيه ، القرة، .1995

6- على محمد عبد الوهاب، التخطيط الاستراتيجى ،كلية التجارة ، جامعة عين شمس،2008.

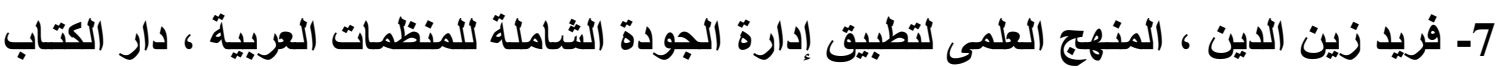

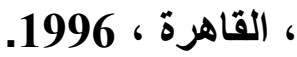

8- قاسم علوان ، إدارة الجودة فى الخدمات، عمان ، دارالثروق، 2006 9- محمــ شـحات، الجـودة الثـاملة والاعتمـاد الأكـاديمى فـى التعليم، دار الخـريجين، الريـاض .2005

10- مختار أبويكر ،أسس ومناهج البحث العلمى ، دار الجامعى، 2010.

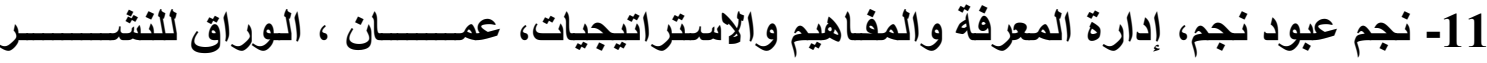

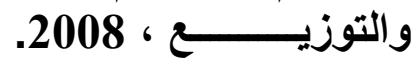
(ب) الدويات والأبحاث العلمية: 
1- حسن على الزغبى، تحليل العلاقة بين رأس المـال الفكرى وإدارة الجودة الثـاملة وانعكاسـها

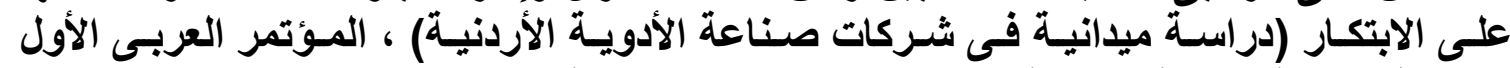
للمنظمة العربية للتنمية الإدارية ومعهل الإدارة العامه بسلطنة عمان 28 - 30 ابريل 2013.

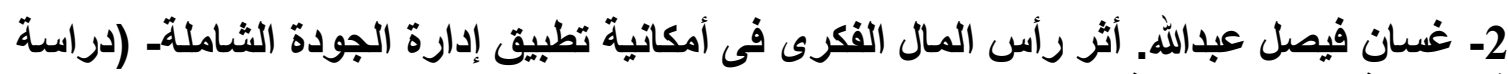

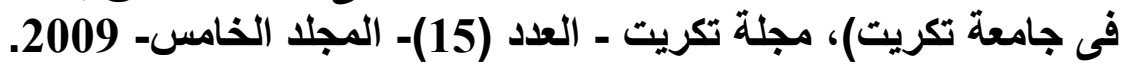

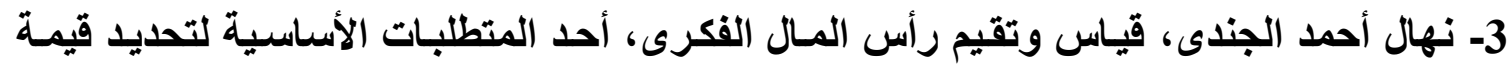
المنثأة، مجلة المحاسبة والإدارة ، كلية التجارة ، جامعة القاهرة ، العدالد 65 ، 2005.

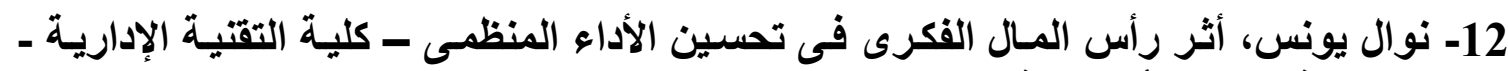
الموصل مجلة العلوم الأقتصادية العدد (30) ، يناير 2012.

$$
\text { (ج) المؤتمرات والندوات العلمية: }
$$

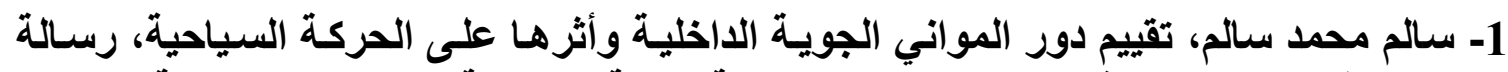

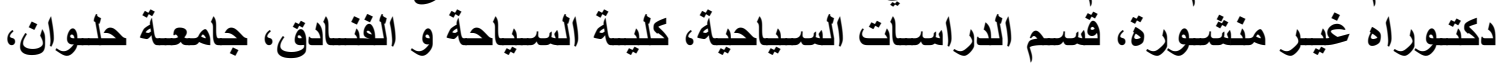

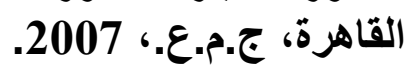

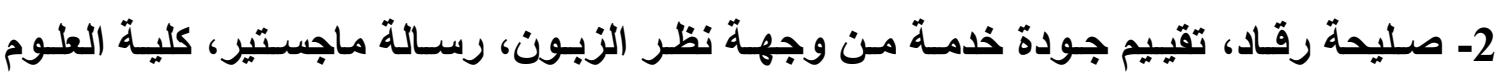

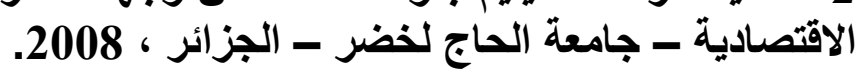

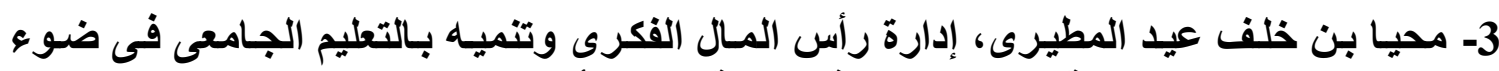
التحويلات المعاصرة، رسالة دكتوراه ، كلية التربية جامعه أم القرى، 


$$
\text { ثانيا:: المراجع الأجنبية: }
$$

2.1 Books:

1- Awad, E.M. \& H.Ghaziri: Knowledge Management, U.S.A.: Prentice Hall, Inc, 2004.

2- Brooking, A: "Intellectual Capital: Core Asset for Third Millennium Enterprise", International Thomson Business Press, London, 1996.

5- Edvinson, L, \& Malone, M. S.:Intellectual Capital:Realizing your Company's True Value by Finding its Hidden Brainpower. NewYork: Harper Business, 1997.

6- Stiles, Philip and Somboon Kulvisaechana: Human capital and performance, A literature review, Judge Institute of Management, University of Cambridge, 2003.

7- Schroeder, R.G.: Operation Management Decision Marking in the Operation Function ;2 ${ }^{\text {nd }}$-Ed New York: Mc Graw Hill Inc., 1985.

8- Sveiby, K.E.: Measuring Intangible \& Intellectual Capital -An Emerging First Standard, (internet version, 5 August 1998). 
9- Stewart, Thomas A.: Intellectual Capital: The New Wealth of Organization. London: Nicholas Brealy Publishing, 1997.

10- Voss, C.A. Operations management in service industries and the public sector. New York: John Wiley \& Sons, 1985.

2.2 Periodicals:

1.Allee,Verna: The Value Evaluation: Addressing Larger Implicational of an Intellectual Capital and Intangible Perspective, Journal of Intellectual Capital. Vol.1,No.1. 2000.

2.Brooking, A: "Intellectual Capital: Core Asset for Third Millennium Enterprise", International Thomson Business Press, London, 1996.

3. Chen, M.C., Cheng, S. J., \& Wang, Y. C: An Empirical Investigation of the Relationship between Intellectual Capital and Firms' Market Value and Financial Performance. Journal of Intellectual Capital ,6,2, 2005.

4.Kossovsky , N , fair Value of Intellectual Capital Information Strategy, Journal of Intellectual Capital, V1, N2, 2002.

5.Kwan, P.Y.: Application of Total Quality Management in Education: Retrospect and Prospect, The International Journal of Educational Management, Vol.10, No.5,1996.

6.Parasuraman A., Valarie. A. Zeithaml \& Leonard L. Berry " A conceptual Model of Service Quality and its Implications for Future Research", Journal of Marketing, Vol. 49, No. 3, (Fall 1985).

7.Parasuraman A., Leonard L. Berry and Zeithaml Valarie A" Servqual: A multiple-item Scale for Measuring Consumer Perception of Service Quality "Journal of Retailing Vol.64, No.1,(Spring 1988).

8. Parasuraman A., Berry L. Leonard and Zeithaml A. Valarie, "Refinement and Reassessment of the SERVQUAL scale" Journal of Retailing, Vol.67, No.4, (Winter 1991). 